\title{
Functional characterization and fitness cost of spinosad-resistant alleles in Ceratitis capitata
}

\author{
Ana Guillem-Amat ${ }^{1,2,3} \cdot$ Enric Ureña ${ }^{1,4}$. Elena López-Errasquín ${ }^{1} \cdot$ Vicente Navarro-Llopis ${ }^{2} \cdot$ Philip Batterham $^{3}$. \\ Lucas Sánchez $^{5} \cdot$ Trent Perry $^{3} \cdot$ Pedro Hernández-Crespo $^{1} \cdot$ Félix Ortego ${ }^{1}$ (i)
}

Received: 20 July 2019 / Accepted: 5 February 2020 / Published online: 15 February 2020

(c) The Author(s) 2020

\begin{abstract}
The sustainability of control programs for the Mediterranean fruit fly, Ceratitis capitata, for citrus crops in Spain has been threatened by the development of resistance to malathion and lambda-cyhalothrin in recent years. Spinosad is widely used without apparent loss of efficacy. However, a highly resistant strain, JW-100s, has been obtained after laboratory selection. Spinosad resistance in JW-100s has been associated with different mutant alleles of the $\alpha 6$ subunit of the nicotinic acetylcholine receptor $(C c \alpha 6)$ including an isoform-specific truncation allele, $C c \alpha 6^{3 a Q 68^{*}}$. Using the GAL4 $>$ UAS system in Drosophila melanogaster to demonstrate expression of this truncated $\alpha 6$ subunit, in a $d \alpha 6$ loss-of-function genetic background, does not rescue susceptibility to spinosad, while the expression of $C c \alpha 6$ wild-type isoforms does. We have also generated C. capitata isolines from JW-100s homozygous for: (1) the $C c \alpha 6^{3 a Q 68^{*} \Delta 3 b-4}$ allele, which contains the mutation $3 \mathrm{aQ68*}$, and (2) the $C c \alpha 6^{3 a Q 68^{*}-K 352^{*}}$ allele, which contains the mutations $3 \mathrm{aQ68*}$ and K352*. Neither of these produce complete $C c \alpha 6$ transcripts. The frequency of resistant alleles declined when in competition with individuals carrying the wild-type allele. Through extensive testing of both biological and behavioral fitness traits, we identified a reduced ability of $C c \alpha 6^{3 a Q 68^{*} \Delta 3 b-4}$ males to detect the parapheromone and to mate with females carrying the $C c \alpha 6^{3 a Q 68^{*}-K 352^{*}}$ allele in competition experiments. Thus, not only the potential for spontaneous resistant mutations to arise in $C c \alpha 6$ but also their fitness costs must be considered when planning resistance management strategies for C. capitata.
\end{abstract}

Keywords Medfly $\cdot$ nAChR $\cdot$ GAL4 $>$ UAS $\cdot$ Fitness traits $\cdot$ Behavior

Communicated by G. Smagghe.

Electronic supplementary material The online version of this article (https://doi.org/10.1007/s10340-020-01205-x) contains supplementary material, which is available to authorized users.

Félix Ortego

ortego@cib.csic.es

1 Departamento de Biotecnología Microbiana y de Plantas, Centro de Investigaciones Biológicas Margarita Salas, CSIC, Madrid, Spain

2 CEQA-IAM, Universitat Politècnica de València, Valencia, Spain

3 School of BioSciences and Bio21 Molecular Science and Biotechnology Institute, University of Melbourne, Parkville, VIC, Australia

4 Present Address: Department of Genetics, Evolution and Environment, Institute of Healthy Ageing, University College London, London, UK

5 Departamento de Biología Celular y Molecular, Centro de Investigaciones Biológicas Margaritas Salas, CSIC, Madrid, Spain

\section{Key message}

- The sustainability of medfly control programs is threatened by insecticide resistance.

- Our results highlight the plasticity of medfly to generate mutations in nAChR $\alpha 6$ that can lead to loss-of-function phenotypes conferring spinosad resistance.

- Resistant alleles have a fitness cost, which could be the reason for the absence of resistance events in the field.

- The results of this study will be useful in designing resistance management strategies for medfly.

\section{Introduction}

The Mediterranean fruit fly (medfly) Ceratitis capitata (Wiedemann) (Diptera: Tephritidae) is one of the main pests for citrus and other fruit trees. It causes significant 
economic losses because of direct damage to fruit as well as restricting the capacity of growers to export to medflyfree areas due to costs related to harvesting surveillance and control actions. While the sterile insect technique is being implemented in some area-wide integrated pest management programs, $C$. capitata control still relies heavily on the use of insecticides (Reddy and Rashmi 2016). Malathion was the most widely used insecticide in Spain from the 1990s until its withdrawal from use in the EU in 2009. Since then, spinosad and lambda-cyhalothrin in bait sprays and deltamethrin in mass trapping and lure and kill devices (Navarro-Llopis et al. 2015) have been the most widely used insecticides for medfly control in citrus crops (MAPA 2019).

The sustainability of medfly control programs is threatened by insecticide resistance (Vontas et al. 2011). Spanish field populations of $C$. capitata have developed resistance to malathion (Magaña et al. 2007, 2008) and lambda-cyhalothrin (Arouri et al. 2015) due to the intensive use of these products. Cross-resistance to deltamethrin has been observed in a laboratory lambda-cyhalothrin-resistant strain (Arouri et al. 2015). There is still no evidence of field resistance to spinosad in Spain, but a highly resistant strain, JW-100s, has been obtained after laboratory selection (Ureña et al. 2019). Thus, in a situation where the repertoire of effective insecticides is becoming very limited, it is essential to ensure their efficacy and sustainability by implementing proper management strategies.

Spinosad is a natural mixture of two active ingredients, spinosyns A and D. It acts by binding to nicotinic acetylcholine receptors (nAChRs) which are composed of five subunits that form a cation channel. There is a significant amount of evidence to suggest that spinosad binds specifically to receptors that include $\alpha 6 \mathrm{nAChR}$ subunits (Salgado and Sparks 2005; Perry et al. 2007; Watson et al. 2010; Somers et al. 2015). The $\alpha 6$ subunit gene produces multiple mRNA transcripts. In insects, it comprises 12 different exons, with two variants of exon 3 ( $3 a$ and $3 b$ ) and generally three variants of exon 8 ( $8 \mathrm{a}, 8 \mathrm{~b}$ and $8 \mathrm{c}$ ) (Jin et al. 2007). Studies on Drosophila melanogaster mutants have shown that loss or truncation of the $\alpha 6$ subunit (D $\alpha 6)$ results in high-level resistance to spinosad (Perry et al. 2007, 2015; Watson et al. 2010; Somers et al. 2015). Moreover, the susceptibility to spinosad is rescued with the expression of any of the D $\alpha 6$ wild-type isoforms (3a8a, 3a8b, 3b8a or 3b8b) in a spinosad-resistant $D$. melanogaster lacking endogenous D $\alpha 6$ function (Anstead et al. 2015; Perry et al. 2015). In these flies, the expression of $\alpha 6$ isoforms from a number of pest insect species was also found to rescue susceptibility to spinosad (Anstead et al. 2015; Perry et al. 2015). However, the localization and functional expression of each isoform, as well as their relevance in the interaction with spinosad under physiological conditions, remain unknown.
More than 250 cases of spinosad resistance have been documented for different pest species (IRAC 2019). Target site-based resistance has been reported for a number of insects, including Plutella xylostella (Baxter et al. 2010; Rinkevich et al. 2010; Wang et al. 2016), Bactrocera dorsalis (Hsu et al. 2012), Frankliniella occidentalis (Puinean et al. 2013), Thrips palmi (Bao et al. 2014) and Tuta absoluta (Berger et al. 2016; Silva et al. 2016). In most cases, it has been associated with mutations that result in premature stop codons (Baxter et al. 2010; Rinkevich et al. 2010; Hsu et al. 2012), exon-skipping events (Berger et al. 2016) and deletions (Wang et al. 2016) in the $\alpha 6$ gene, which presumably result in non-functional proteins. However, the point mutations P146S and G275E in the $\alpha 6$ gene that do not disrupt transcription (Puinean et al. 2013; Bao et al. 2014; Somers et al. 2015; Silva et al. 2016) and enhanced metabolism mediated by P450 and esterase enzymes (Geng et al. 2013) have also been associated with spinosad resistance in some insects.

Reversion of resistance in the absence of spinosad selection has been reported for Musca domestica (Khan et al. 2014), Liriomyza trifolii (Ferguson 2004), Spodoptera litura (Rehan and Freed 2014), P. xylostella (Sayyed et al. 2008), T. absoluta (Campos et al. 2014) and F. occidentalis (Bielza et al. 2008b), indicating the existence of a fitness cost associated with spinosad resistance. There is evidence that the knockout of $\alpha 6$ function in D. melanogaster does not cause lethality and no fitness effects have yet been reported in this species (Perry et al. 2007). However, when different trade-offs related to growth and developmental traits were analyzed in other species, fitness costs ranged from absent or minor (Wyss et al. 2003; Bielza et al. 2008a; Abbas et al. 2014) to substantial (Li et al. 2007; Wang et al. 2010; Okuma et al. 2018). The need to investigate fitness, behavioral and life-history traits that require the function of receptors being targeted by insecticides has been highlighted (Perry and Batterham 2018). While nAChRs may have many roles in behavior, the known roles for the different subunits identified in D. melanogaster currently include sleep (D $\alpha 1, \mathrm{D} \alpha 3$ and D $\alpha 4$-Shi et al. 2014; Somers et al. 2017; Wu et al. 2014), courtship (D $\alpha 1$-Somers et al. 2017) and escape response (D $\alpha 7-$ Fayyazuddin et al. 2006). Only a few studies have considered how spinosad resistance affects behavior and the impact that loss-of-function or truncated $\alpha 6$ transcripts could have. Changes to feeding behavior in $F$. occidentalis ( $\mathrm{Li}$ et al. 2017) and reduced competitive mating in Heliothis virescens (Wyss et al. 2003) have been reported, but the molecular basis of resistance was unknown in both cases.

Spinosad resistance in the laboratory selected JW-100s strain has been associated with three different mutant alleles of the $\alpha 6 n A C h R$ gene of medfly $(C c \alpha 6)$ : (1) the $C c \alpha 6^{3 a A G>A T}$ allele, with the AG $>$ AT mutation in the 
5 'splice site of exon 3a, which produces full-length transcripts carrying exon $3 \mathrm{~b}$ and incomplete transcripts that skip exon $3 \mathrm{a}$ and join exons 2 and 4 ; (2) the $C c \alpha 6^{3 a Q 68^{*}}$ allele, with $3 \mathrm{aQ68*}$ mutation giving rise to truncated transcripts at exon $3 \mathrm{a}$ and full-length transcripts with exon $3 \mathrm{~b}$; and (3) the $C c \alpha 6^{3 a Q 68^{*}-K 352^{*}}$ allele with mutations $3 \mathrm{aQ} 68^{*}$ and $\mathrm{K} 352^{*}$, which lead to truncated transcripts at exon $3 \mathrm{a}$, and to $3 \mathrm{~b}$ transcripts truncated at exon 10 (Ureña et al. 2019). None of the $C c \alpha 6$ transcripts from the $C c \alpha 6^{3 a Q 68^{*}-K 352^{*}}$ allele could generate complete Cc $\alpha 6$ protein products. This mutant would therefore be expected to be resistant to spinosad (Perry et al. 2007). However, why individuals homozygous for the $C c \alpha 6^{3 a Q 68^{*}}$ or $C c \alpha 6^{3 a A G>A T}$ alleles are resistant is not known, as these alleles only affect isoforms containing exon $3 \mathrm{a}$ while generating wild-type full-length $C c \alpha 6$ isoforms with exon $3 \mathrm{~b}$. The analysis of the frequency of the three resistant alleles during the selection process for JW-100s revealed fluctuations. In brief, alleles $C c \alpha 6^{3 a A G>A T}$ and $C c \alpha 6^{3 a Q 68^{*}}$ were most frequent at generation F29. However, after generation $\mathrm{F} 45$, the allele $C c \alpha 6^{3 a A G>A T}$ was not found and $C c \alpha 6^{3 a Q 68^{*}-K 352^{*}}$, not detected in previous generations, had the highest frequency. Finally, at generation F85, the population mainly consisted of individuals homozygous for $C c \alpha 6^{3 a Q 68^{*}-K 352 *}(92 \%)$. These data could be explained by a combination of differences in resistance levels and fitness costs for the three alleles. Further, the spontaneous generation of mutations during the laboratory selection process may also have been a factor (Ureña et al. 2019). Resistance to spinosad in the JW-100s strain is recessive (Ureña et al. 2019), consistent with other reported examples of $\alpha 6$-based resistance (Bielza et al. 2007; Perry et al. 2007; Baxter et al. 2010; Wang et al. 2016).

The goal of this study was to determine whether or not the relationship between spinosad resistance and $C c \alpha 6^{3 a Q 68^{*}}$ and $C c \alpha 6^{3 a Q 68^{*}-K 352^{*}}$ alleles is causal. To achieve this goal, we have created transgenic D. melanogaster lines that express mutated and wild-type isoforms of $C c \alpha 6$ using the GAL4 > UAS expression system and also generated $C$. capitata isolines homozygous for these two mutant alleles. In addition, we have assessed the stability of spinosad resistance in $C$. capitata linked to these two alleles in the absence of spinosad selection. This along with the analysis of biological (developmental time, adult weight) and behavioral (parapheromone detection by wind tunnel and electrophysiological assays, and mating success) traits in the mutants allows us to examine whether there are fitness costs associated with these resistant alleles. The results of this study will be useful in designing resistance management strategies for medfly.

\section{Materials and methods}

\section{C. capitata strains and generation of isolines}

The susceptible laboratory strain of $C$. capitata, C, was established from medfly individuals from non-treated experimental fields of the Instituto Valenciano de Investigaciones Agrarias (IVIA, Valencia, Spain) in 2001. Since then, it has been reared in the laboratory without any exposure to insecticides.

The $C$. capitata isolines described here were derived from the spinosad-resistant laboratory strain JW-100s (Ureña et al. 2019). To obtain isolines homozygous for the mutant alleles, a process of crossing and genotyping was performed. All of the crosses were initiated with 50 virgin females (isolated as pupae) and ten males under standard rearing conditions $(16: 8 \mathrm{~h}$ light: dark photoperiod and a temperature of $26 \pm 2{ }^{\circ} \mathrm{C}$ (light) and $22 \pm 2{ }^{\circ} \mathrm{C}$ (dark) with water and food ad libitum). After 7-10 days, individual females were placed in tubes containing around $20 \mathrm{~g}$ of larval rearing medium (standard rearing conditions) for oviposition. When the progeny of these females had developed into larvae and pupae, their female parents were genotyped and the progeny of females carrying the allele of interest were selected for the next cross. The genotyping was done according to two PCR protocols described in Ureña et al. (2019), a PCR-RFLP for the detection of the $\mathrm{K} 352 *$ mutation in exon 10 , identified via the presence of an MseI restriction site in the mutant allele, and a multiplex ("multiplex PCR-2" in Ureña et al. (2019)) to detect the Q68* mutation in exon 3a. Both protocols allow mutant- and wild-type homozygotes and heterozygotes to be distinguished. Homozygous lines were sequenced to ensure that all individuals were of the expected genotype. The sequencing was performed by Secugen (Madrid, Spain) on a 3730 XL DNA Analyzer (Applied Biosystems) using BigDye ${ }^{\circledR}$ Terminator v3.1 reagents. The DNA sequences produced were analyzed using Geneious 11.0.5 (https://www.geneious.com).

In order to obtain the $\mathrm{Q} 68 *-\mathrm{K} 352 *$ isoline, a cross between JW-100s females and C males, homozygous for the wild allele $\left(C c \alpha 6^{+} / C c \alpha \sigma^{+}\right)$, was performed. F1 progeny which female parent carried the $C c \alpha 6^{3 a Q 68^{*}-K 352}$ / $C c \alpha 6^{3 a Q 68^{*}-K 352 *}$ genotype were selected and inter-crossed. The progeny $\mathrm{F} 2$ embryos were placed on larval rearing medium (stock prepared by mixing $300 \mathrm{~g}$ of sugar, $11.2 \mathrm{~g}$ of $N$-propyl-p-hydroxybenzoate (Sigma-Aldrich, Japan), $11.2 \mathrm{~g}$ of methyl-4-hydroxibenzoate (Sigma-Aldrich, India), $10 \mathrm{~g}$ of benzoic acid (Merck, China), $145.2 \mathrm{~g}$ of dry beer yeast (Difco Laboratories, Erembodegem, Belgium), $1000 \mathrm{~g}$ of wheat bran and $2400 \mathrm{ml}$ of distilled water) containing $5 \mathrm{ppm}$ of spinosad to eliminate the $C c \alpha \sigma^{+} / C c \alpha \sigma^{+}$ 
and $C c \alpha 6^{+} / C c \alpha 6^{3 a Q 68^{*}-K 352 *}$ genotypes. F2 survivors were used to establish the homozygous Q68*-K352* isoline $\left(C c \alpha 6^{3 a Q 68{ }^{*}-K 352 *} / C c \alpha 6^{3 a Q 68 *-K 352 *}\right)$ (Online Resource 3a).

To obtain Q68* isoline, an initial cross was done between JW-100s females and males of the Q68*-K352* isoline. F1 females carrying the $C c \alpha 6^{3 a Q 68^{*}}$ allele were selected for crossing to $\mathrm{C}\left(C c \alpha 6^{+} / C c \alpha \sigma^{+}\right)$males, and the same process was repeated with $\mathrm{F} 2$ females. F3 individuals carrying the $C c \alpha 6^{+} / C c \alpha 6^{3 a Q 68^{*}}$ genotype were inter-crossed, and the resulting $\mathrm{F} 4$ embryos were placed on larval rearing medium containing $5 \mathrm{ppm}$ spinosad to eliminate the $C c \alpha 6^{+} / C c \alpha \sigma^{+}$ and $C c \alpha 6^{+} / C c \alpha 6^{3 a Q 68^{*}}$ genotypes. F4 survivors were used to establish the Q68* isoline (Online Resource 3b), homozygous for a new allele $C c \alpha 6^{3 a Q 68^{*} \Delta 3 b-4} / C c \alpha 6^{3 a Q 68^{*} \Delta 3 b-4}$ (see Results).

\section{Genomic DNA extraction, PCR of intronic/exonic boundaries and sequencing of $\mathrm{Cca} 6$}

Genomic DNA (gDNA) extraction from single flies from Q68* and Q68*-K352* isolines and JW-100s and C strains of $C$. capitata was carried out with tissue homogenization and DNA isolation using SpeedTools Tissue DNA Extraction (Biotools, Madrid, Spain), according to the manufacturer's instructions. gDNA was quantified using Nanodrop ND-1000 spectrophotometer (Thermo Fisher Scientific, Waltham, MA, USA).

The boundaries between intronic regions and exons 2, 3a, $3 \mathrm{~b}, 4$ and 5 of $C c \alpha 6$ were PCR amplified. The reactions were performed in a volume of $10 \mu \mathrm{l}$ using $0.4 \mu \mathrm{M}$ of each oligonucleotide (Online Resource 1), $0.5 \mathrm{U}$ of AmpliTaq Gold DNA Polymerase (Thermo Fisher Scientific, Austin, USA), $10 \times$ PCR Buffer II, $1.5 \mathrm{mM} \mathrm{MgCl}_{2}, 0.2 \mathrm{mM}$ dNTPs (Thermo Fisher Scientific, Austin, USA) and 100-200 ng of the corresponding template. PCR conditions were as follows: an initial denaturation step at $95{ }^{\circ} \mathrm{C}$ for $5 \mathrm{~min} ; 40$ cycles of $95{ }^{\circ} \mathrm{C}$ for $30 \mathrm{~s}, 60^{\circ} \mathrm{C}$ for $30 \mathrm{~s}$ and $72{ }^{\circ} \mathrm{C}$ for $30 \mathrm{~s}$; and a final step of $72{ }^{\circ} \mathrm{C}$ for $7 \mathrm{~min}$ for full extension. PCR products were analyzed by electrophoresis on $1.5 \%$ agarose gel (Agarose D2, Conda Pronadisa, Madrid, Spain) and directly purified (QIAquick PCR Purification Kit, QIAGEN, Germany). As required, bands of interest were purified from the gel with Ultrafree ${ }^{\circledR}$-DA Centrifugal Filter Units (Millipore, Ireland) following the manufacturer's instructions. The $C c \alpha 6$ regions were then sequenced with the same primers used for the amplification (Secugen, Madrid, Spain).

\section{RNA extraction, RT-PCR, qPCR of Cca6 exons, PCR and sequencing of codifying regions}

Three replicates of Q68* and Q68*-K352* isolines and C strain were used to analyze isoform expression. Each replicate consisted of a pool of three males and three females.
Total RNA extraction was performed with TRIzol ${ }^{\circledR}$ Reagent (Life Technologies, Van Allen Way, Carlsbad, California, USA) according to the manufacturer's instructions, and RNA was dissolved in RNAsecure Resuspension Solution (Life Technologies) followed by incubation at $60{ }^{\circ} \mathrm{C}$ during 10 min and quantification with Nanodrop ND-1000 spectrophotometer. Reverse transcription of complementary DNA (cDNA) was performed using $2 \mu \mathrm{g}$ of RNA as a template and a commercial kit (Thermo Scientific, Massachusetts, USA), with modifications of the protocol as described in Ureña et al. (2019).

qPCR for the analysis of the expression of exons $3 a, 3 b$ and 7 was carried out in a Corbett Rotor-Gene 6000 (QIAGEN) in a volume of $15 \mu \mathrm{l}$ using $0.3 \mu \mathrm{M}$ of each oligonucleotide (Online Resource 1), Brilliant III Ultra-Fast SYBR Green QPCR 2X (Agilent Technologies, Texas, USA) and $5 \mu \mathrm{l}$ of cDNA template diluted 50 -fold. qPCR conditions were as follows: an initial step at $95^{\circ} \mathrm{C}$ for $3 \mathrm{~min} ; 45$ cycles of $95^{\circ} \mathrm{C}$ for $10 \mathrm{~s}$ and $60{ }^{\circ} \mathrm{C}$ for $30 \mathrm{~s} ; 50{ }^{\circ} \mathrm{C}$ for $3 \mathrm{~min}$ and a melting ramp of $50-99{ }^{\circ} \mathrm{C}$ raising by $1{ }^{\circ} \mathrm{C}$ and waiting for $5 \mathrm{~s}$ in each step. Actin-5C, glycerol-3-phosphate dehydrogenase (GPDH) and $\alpha$-tubulin were used as reference genes to normalize the data.

PCR for the coding regions was performed in a volume of $25 \mu \mathrm{l}$ using $0.8 \mu \mathrm{M}$ of each oligonucleotide (Online Resource 1), $0.5 \mathrm{U}$ of AmpliTaq Gold DNA Polymerase (Thermo Fisher Scientific, Austin, USA), 10× PCR Buffer II, $1.5 \mathrm{mM} \mathrm{MgCl}{ }_{2}, 0.2 \mathrm{mM}$ dNTPs (Thermo Fisher Scientific, Austin, USA) and $5 \mu \mathrm{l}$ of the corresponding cDNA as template. PCR conditions are described in Sect. 2.2., and then, PCR products were purified and sequenced.

\section{GAL4 > UAS targeted expression of Cca6 isoforms in D. melanogaster}

D. melanogaster transgenic flies with an insertion of wild-type $C c \alpha 6$ isoforms 3a8b (MK251469) (strain UAS$\mathrm{Cc} \alpha 6^{3 \mathrm{a} 8 \mathrm{~b}}$ ) and 3b8a (MK251470) (strain UAS-Cc $\alpha 6^{3 \mathrm{~b} 8 \mathrm{a}}$ ) and the mRNA isoform carrying 3aQ68* mutation (strain UAS-Cc $\left.\alpha 6^{3 \mathrm{aQ} 68^{*}}\right)$ of the $C c \alpha 6$ gene were created in the $d \alpha 6^{n x}$ background (as per Perry et al. 2015) to specifically express Cc $\alpha 6$ isoforms using the GAL4 > UAS method (Brand and Perrimon 1993).

\section{Cloning of wild-type and mutant mRNA isoforms of Cca6}

Mutated and wild-type sequences of $C c \alpha 6$ were obtained by conventional PCR from JW-100s resistant and C wildtype individuals, respectively. Samples were acquired by RNA extraction of single flies, and cDNA synthesis was performed as described above. The oligonucleotides used (Sigma-Aldrich, Spain) are listed in Online Resource 2. 
The mutant allele was amplified through PCR in a volume of $25 \mu \mathrm{l}$ using $0.4 \mu \mathrm{M}$ of forward FnAch6ex 1 and reverse RnAch6Q68 oligonucleotides, with reagents and conditions as mentioned above. Wild-type isoforms were amplified in a volume of $50 \mu \mathrm{l}$ using $0.5 \mu \mathrm{M}$ of forward FnAch6ex 1nest and reverse RnAch6ex 12 oligonucleotides, $2 \mathrm{U}$ of $\mathrm{iTaq}^{\mathrm{TM}}$ DNA Polymerase (Bio-Rad, California, USA), 5× HF Buffer, $0.2 \mathrm{mM}$ dNTPs and $8 \mu \mathrm{l}$ of the corresponding cDNA diluted 100-fold as template. PCR conditions were as follows: an initial denaturation step at $98{ }^{\circ} \mathrm{C}$ for $30 \mathrm{~s} ; 35$ cycles of $98{ }^{\circ} \mathrm{C}$ for $10 \mathrm{~s}, 60{ }^{\circ} \mathrm{C}$ for $30 \mathrm{~s}$ and $72{ }^{\circ} \mathrm{C}$ for $1.5 \mathrm{~min}$; and a final step of $72{ }^{\circ} \mathrm{C}$ for $7 \mathrm{~min}$ for full extension.

PCR products were cloned into the pGEM-T-easy vector (Promega Corporation, Madison, USA) following manufacturer instructions. Transformation was performed by electroporation with a $2.5 \mathrm{~V}$ electric pulse for $4.6 \mathrm{~ms}$ using a MicroPulser ${ }^{\mathrm{TM}}$ electroporator (Bio-Rad, USA). Minipreps were performed using the alkaline lysis method (Engebrecht et al. 1991). The amount of plasmid DNA was quantified using a NanoDrop (Thermo Fisher Scientific, Massachusetts, USA) and sequenced (Secugen, Madrid, Spain) to identify the isoform present and to detect any mutations introduced in the cloning process.

\section{Construction of vectors for transformation of $D$. melanogaster}

Clones were digested with NotI (New England Biolabs, NEB) and ligated into digested pUASattB (Bischof et al. 2007) using 1U DNA T4 ligase (Promega Corporation, Madison, USA) and $2 \times$ buffer. Transformation was performed using a standard heat shock protocol. Clones with proper orientation were selected and cultures established. Plasmids were purified (Wizard ${ }^{\circledR}$ Plus SV Minipreps DNA Purification System, Promega, USA) and sequenced (Macrogen, South Korea) with T7 and T3 oligonucleotides (Online Resource 2).

\section{Microinjection of $C c a 6$ constructs to generate transgenic lines}

Transgenic UAS-Cc $\alpha 6$ lines of $D$. melanogaster were produced by embryonic microinjection into $786 \mathrm{G}$ strain, which lacked expression of the $n A C h \alpha 6$ gene $\left(d \alpha 6^{n x}\right)$ (Perry et al. 2015). Plasmid DNA (100-250 mg/ $\mu \mathrm{l})$ was injected into the posterior pole of dechorionated 0-30-min-old embryos using a Femtojet microinjector (Eppendorf, USA) with a FemtoII needle (Eppendorf, Hamburg, Germany). Singlepair crosses were established with survivors that developed to the adult stage, and then, F1 individuals carrying the transgene (distinguishable by their eye color) were crossed to obtain homozygous lines.
To drive the expression of UAS constructs, homozygous transgenic males were crossed to females homozygous for the X-linked D $\alpha 6>$ GAL4 which drives expression in cells that normally express $D \alpha 6$ (Perry et al. 2015). This was conducted in the $d \alpha 6^{n x}$ background.

\section{Susceptibility bioassays with spinosad}

\section{Susceptibility of $C$. capitata}

The susceptibility of $C$. capitata Q68* and Q68*-K352* isolines to spinosad was tested with a topical application assay with increasing doses of this insecticide (Dow AgroSciences $88 \% \mathrm{p} / \mathrm{p}$, Indianapolis, USA). Dilutions were prepared using acetone as a solvent for spinosad and for the non-treated control. A volume of $0.5 \mu \mathrm{l}$ of each solution was applied to each fly with an automated microapplicator $900 \mathrm{X}$ (Burkard Manufacturing Co., Hertfordshire, UK). Four replicates of each dose were performed with 15 flies per replicate. After the insecticide treatment, flies were confined in ventilated plastic dishes $(89 \mathrm{~mm}$ in diameter and $23 \mathrm{~mm}$ in height) with water and the rearing diet (4:1 sugar/yeast) $a d$ libitum, in an environmentally controlled chamber (Sanyo MLR-350-H, Sanyo, Japan), at $25 \pm 1{ }^{\circ} \mathrm{C}$ and $16 \mathrm{~h}$ light and $8 \mathrm{~h}$ dark photoperiod (standard conditions). Mortality was recorded after $48 \mathrm{~h}$. Flies were considered dead if they were ataxic.

\section{Susceptibility of D. melanogaster}

The D. melanogaster transgenic strains were also tested for susceptibility to spinosad. The resistant 786G strain (carrying $d \alpha 6^{n x}$ ) and $d \alpha 6^{n x}$;UAS-D $\alpha 6-3 \mathrm{a} 3 \mathrm{~b}$ flies (that carries a susceptible nACh $\alpha 6$ transcript from $D$. melanogaster, isoform $3 \mathrm{a} 3 \mathrm{~b}$ ) were used as positive and negative controls, respectively. Bioassays were performed by placing F1 firstinstar larvae in vials containing food with increasing doses of spinosad $(0,0.05,0.5$ and $5 \mathrm{ppm})$. Food was prepared using Instant Drosophila Medium (Carolina ${ }^{\mathrm{TM}}$, Burlington, North Carolina, USA). The experiment included five replicates of each spinosad concentration and five vials with non-treated food, with 50 larvae per vial. Vials were kept in the environmentally controlled chamber in constant darkness at $25 \pm 1{ }^{\circ} \mathrm{C}$. The number of flies that had emerged after 16-19 days was recorded.

\section{Stability of $C \mathrm{Ca} 6^{3 a Q 68^{*} \Delta 3 b-4}$ and $C \mathrm{Ca} 6^{3 a Q 68^{*}-K 352^{*}}$ alleles in C. capitata}

Pupae from the Q68*(Cc $\left.\alpha 6^{3 a Q 68^{*} \Delta 3 b-4} / C c \alpha 6^{3 a Q 68 * \Delta 3 b-4}\right)$ and $\mathrm{Q} 68 *-\mathrm{K} 352 *\left(C c \alpha 6^{3 a Q 68 *-K 352 *} / C c \alpha 6^{3 a Q 68^{*}-K 352 *}\right)$ isolines and $\mathrm{C}$ strain $\left(C \mathrm{C} \alpha \sigma^{+} / C \mathrm{C} \alpha \sigma^{+}\right)$were isolated, and the adults sexed immediately after emergence to guarantee virginity. 
Males and females from each strain were placed separately into ventilated plastic dishes and maintained with water and rearing diet for 2 days. The following reciprocal crosses were performed: $100 \delta^{\top} \mathrm{Q} 68^{*} \times 100+\mathrm{C}$ and $100+\mathrm{Q} 68^{*} \times 100 \stackrel{ }{\top} \mathrm{C}$ to obtain QC-G0 (genotype $C c \alpha 6^{3 a Q 688^{*} \Delta 3 b-4} / C c \alpha 6^{+}$); 100 Q $68 *-\mathrm{K} 352 * \times 100+\mathrm{C}$ and $100+\mathrm{Q} 68 *-\mathrm{K} 352 * \times 100$ ${ }^{\top} \mathrm{C}$ to obtain KC-G0 (genotype $C c \alpha 6^{3 a Q 68 *-K 352 *} / C c \alpha 6^{+}$); and $100{ }^{\top} \mathrm{Q} 68 * \times 100+\mathrm{Q} 68 *-\mathrm{K} 352 *$ and $100+\mathrm{Q} 68^{*} \times 100$ ${ }^{1} \mathrm{Q} 68 *-\mathrm{K} 352 *$ to obtain QK-G0 (genotype $C c \alpha 6^{3 a Q 68 * \Delta 3 b-4}$ $\left./ C c \alpha 6^{3 a Q 68^{*}-K 352 *}\right)$. The progeny of reciprocal crosses were pooled at G0. Three replicates of QC and KC crosses were established and maintained for nine generations without insecticide selection pressure. Three replicates of the QK cross were established and maintained without selection until G1. At generation G2, each replica of QK was split into two, one continued without exposure to insecticide (QKnt), whereas the other one was exposed to $100 \mathrm{ppm}$ spinosad for $72 \mathrm{~h}$ (QKs) every generation for nine generations. Between 20 and 40 flies of each cross and generation were frozen at $-20{ }^{\circ} \mathrm{C}$ for genotyping.

\section{Fitness of resistant isolines and the susceptible strain of $C$. capitata}

Several assays were performed to analyze biological and behavioral traits in Q68* and Q68-K352* isolines and the C strain.

\section{Developmental time to pupation and adults' weight}

Eggs (corresponding to a volume of $50 \mu \mathrm{l}$ ) were collected and spread on larval rearing medium (160 g approx.) in containers $(130 \times 90 \times 25 \mathrm{~mm})$ covered with an aluminum foil to avoid desiccation. Containers were placed in 21 ventilated plastic boxes allowing third-instar larvae that jump from the food container and pupate to be collected. Eggs were kept in the environmentally controlled chamber in constant darkness at $25 \pm 1{ }^{\circ} \mathrm{C}$. Three replicates of each strain were prepared. The number of pupae obtained was recorded every day and the pupae removed from the box. Fifty females and 50 males (2-3-day-old adult flies) of each strain were collected and weighed with a precision balance (AM100, Mettler-Toledo, Switzerland).

\section{Attraction to a parapheromone in a wind tunnel}

The attraction of males for trimedlure (a parapheromone) was evaluated in a wind tunnel (Jang et al. 1994). A piece of trimedlure dispenser weighing $0.52 \mathrm{~g}$ (Aralure, Agrisense, Pontypridd, UK) was suspended from the top of the wind tunnel $(63 \times 63 \times 215 \mathrm{~cm}$, Plexiglas flight tunnel, Analytical Research Systems, Gainesville, FL, USA) at a height of $20 \mathrm{~cm}$, next to the air inlet, while 50 male adult flies were released downwind at the other end of the tunnel. A yellow sticky trap (Koppert, Berkel en Rodenrijs, The Netherlands) was located next to the trimedlure so that flies approaching the lure would be stuck. The rate of airflow was $0.2 \mathrm{~m} / \mathrm{s}$, the temperature $25{ }^{\circ} \mathrm{C}$ and the humidity $40 \%$. Flies were left inside the tunnel for $30 \mathrm{~min}$. The time taken for the first fly of each strain to reach the trap was recorded, as well as the number of caught flies in each 5 min interval. Each isoline/strain was evaluated four times. A control assay (same conditions, flies and yellow trap without trimedlure) was performed to measure any effect of the yellow traps on flies. The number of flies stuck in the presence of trimedlure was corrected by the number of flies stuck without it.

\section{Electrophysiological antennal activity}

Electroantennography (EAG) was performed to determine whether males were able to produce a response when stimulated with trimedlure (Cossé et al. 1995). Heads of 3-7-dayold adult flies were removed from the rest of the body and connected to two electrodes of an EAG probe-type PRG-2 (Syntech) coated with a conductive Spectra 360 electrode gel (Parker Laboratories Inc., Fairfield, NJ, USA); one electrode was inserted into the tip of one antenna and the other into the back of the head. A Syntech IDAC 2 acquisition controller and a Syntech CS-55 stimulus controller (Ockenfels Syntech GmbH, Kirchzarten, Germany) were used to evaluate the electroantennographic response. GC-EAD 32 (v 4.3) software was employed to record the data. Serial dilutions of the tested compound were made in re-distilled HPLC-grade hexane. The solution $(5 \mu \mathrm{l})$ was applied to a filter paper strip located inside a $15-\mathrm{cm}$-long Pasteur pipette. Control puffs of air (pipette containing a filter paper with no impregnated solution) and a blank (filter paper plus hexane) were performed with each head before the exposure to trimedlure. The response to air was used as a negative control as it showed low EAG activity, very close to $0 \mathrm{mV}$. The response to hexane was used as a positive control as $C$. capitata individuals show EAG activity when exposed to this compound. Between 5 and 15 replicates of each strain/ isoline were performed. Thus, EAG amplitudes recorded when exposed to trimedlure were corrected by the value of observed with hexane exposure.

\section{Male competition in mating}

Mating assays were performed to study the mating success of males of the three strains. Virgin 3-5-day-old males and females were used to make crosses with ten females of the same strain and 12 males of each of the three strains. Five replicates of each cross were established. Flies were located in ventilated methacrylate boxes $(12 \mathrm{~cm}$ diameter, $5 \mathrm{~cm}$ in height) provided with water and food ad libitum. Crosses 
were kept during $6 \mathrm{~h}$ in a climatic room, at $26 \pm 2{ }^{\circ} \mathrm{C}$ during the light hours. Then, individual females were placed in separate tubes containing rearing medium for the laying of the eggs, and under standard conditions until F1 pupae were obtained (approximately 10 days). Three pupae derived from each female were genotyped. The presence of $C c \alpha 6^{3 a Q 68^{*}-K 352^{*}}, C c \alpha 6^{3 a Q 68 * \Delta 3 b-4}$ and $C c \alpha 6^{+}$alleles allowed the genotype of the male mating with each female to be determined.

\section{Statistics}

In all experiments, data were statistically analyzed with the Levene and Shapiro-Wilk tests to test the homogeneity and normality of the data, respectively. Developmental time to pupation, weight of adult flies, first fly to reach the source of stimuli in the wind tunnel, competitive mating assays with C. capitata and arcsin-transformed susceptibility to spinosad of $D$. melanogaster transgenic lines were analyzed by ANOVA followed by the Student-Newman-Keuls post hoc test. Expression levels of $C c \alpha 6$ exons were performed on $\mathrm{Cq}^{\prime}$ values ( $\log 2$ transformation of NRQs) using Student's $t$ test (exonic regions 3a-4 and 2-3b) or ANOVA followed by Student-Newman-Keuls post hoc test (exonic regions 2-3a and 7). The attraction to trimedlure of a group of flies in wind tunnel was evaluated by a repeated measures ANOVA, also followed by Student-Newman-Keuls post hoc test. A Kruskal-Wallis test was performed for the analysis of EAG. Chi-square test was completed to test the fit of the data to expected genotypic frequencies in the stability assay. For the analysis of susceptibility to spinosad of $C$. capitata isolines/ strains, mortality data were used to estimate $\mathrm{LD}_{50}$ values (dose needed to cause 50\% mortality) and Probit analysis was performed using the program POLO-PC (LeOra Software14), which corrects exposed samples' mortality with the control mortality using Abbott's transformation (Abbott 1925 ). Resistance ratios $\left[R R=L_{50}\right.$ (lab strain/isoline) $/ \mathrm{LD}_{50}$ (C strain)] were considered significant if their $95 \%$ fiducial limits did not include 1 (Robertson and Preisler 1992).

\section{Results}

\section{Expression of $\mathrm{Cca}^{3 a Q 68^{*}}, \mathrm{Cca}^{3 a 8 b}$ and $\mathrm{Cca} 6^{3 b 8 a}$ mRNA isoforms in D. melanogaster}

In order to study the contribution that the different $C c \alpha 6$ alleles make to spinosad resistance/susceptibility, it is important that they be compared in an identical genetic background. Such experiments are readily performed in $D$. melanogaster. Thus, we generated UAS transgenic D. melanogaster flies carrying wild-type mRNA isoforms $C c \alpha 6^{3 a 8 b}$ $\left(\mathrm{UAS}-\mathrm{Cc} \alpha 6^{3 \mathrm{a} 8 \mathrm{~b}}\right.$ ) and $C c \alpha 6^{3 \mathrm{~b} 8 \mathrm{a}}$ (UAS-Cc $\left.\alpha 6^{3 \mathrm{~b} 8 \mathrm{a}}\right)$, and mutant
mRNA isoform $C c \alpha 6^{3 \mathrm{aQ} 68^{*}}$ (UAS-Cc $\alpha 6^{3 \mathrm{aQ} 68^{*}}$ ). We used the methods of Perry et al. (2015) to introduce the mRNA isoforms of $C c \alpha 6$ into the resistant background of 786G strain, carrying the null $d \alpha 6^{n x}$ allele.

Bioassays of susceptibility to spinosad were performed with F1 flies from the cross between transgenic UAS-Cc $\alpha 6$ strains and the $D \alpha 6>$ GAL4; $d \alpha 6^{n x}$ driver strain (Fig. 1a). Flies expressing UAS-Cc $\alpha 6^{3 \mathrm{a} 8 \mathrm{~b}}$ and UAS-Cc $\alpha 6^{3 \mathrm{~b} 8 \mathrm{a}}$ had close to $100 \%$ mortality when exposed to $0.5 \mathrm{ppm}$ of spinosad in the food. Those flies expressing UAS-Cc $\alpha 6^{3 \mathrm{aQ} 68^{*}}$ only had approximately $20 \%$ mortality, even at the highest concentration tested ( $5 \mathrm{ppm})$. As expected, the progeny from the control cross $\left(D \alpha 6>\right.$ GAL4; $\left.d \alpha 6^{n x} \times 786 \mathrm{G}\right)$ did not exhibit significant mortality at any of the tested concentrations of spinosad, while mortality of the $\mathrm{F} 1$ produced by crossing $D \alpha 6>$ GAL $4 ; d \alpha 6^{n x}$ with $d \alpha 6^{n x}$; UAS-D $\alpha 6-3 \mathrm{a} 3 \mathrm{~b}$ (the susceptible $n A C h 6$ transcript) was greater than $60 \%$ at all concentrations tested. We found that UAS-Cc $\alpha 6^{3 \mathrm{a} 8 \mathrm{~b}}$ and UAS-Cc $\alpha 6^{3 \mathrm{~b} 8 \mathrm{a}}$ strains also showed spinosad susceptibility when we tested them without driving the expression of the transgene (Fig. 1b). This could be due to basal expression of the transgenes and suggests that minimal expression levels of Cc $\alpha 6$ are enough for spinosad to be toxic. Thus, rescue experiments showed that $n A C h 6$ wild-type mRNA isoforms $3 \mathrm{a} 8 \mathrm{~b}$ and $3 \mathrm{~b} 8 \mathrm{a}$ are capable of rescuing the response to spinosad, while the mRNA isoform carrying the $3 \mathrm{aQ} 68^{*}$ mutation does not.

\section{Characterization of Q68* and Q68*-K352* isolines of C. capitata}

To study the contribution of resistant alleles $C c \alpha 6^{3 a Q 68^{*}}$ and $C c \alpha 6^{3 a Q 68^{*}-K 352^{*}}$ to the resistance phenotype of the laboratory strain JW-100s, we generated two isolines homozygous for each allele and we named them Q68* $\left(C c \alpha 6^{3 a Q 68^{*}} / C c \alpha 6\right.$ $3 a Q 68 *)$ and Q68*-K352* (Cc $\left.\alpha 6^{3 a Q 68^{*}-K 352 *} / C c \alpha 6^{3 a Q 68^{*}-K 352 *}\right)$. When obtained, we characterized them molecularly to check whether they carried the expected genotypes.

We first sequenced the cDNA of $C c \alpha 6$ and found that Q68* isoline had transcripts where exon 3a was directly followed by exon 5, and transcripts with exon 2 followed by exon 5 , indicating that exons $3 \mathrm{~b}$ and 4 were not transcribed. In addition, we observed that when exons $3 b$ and 4 were absent, a change in the reading frame of $C c \alpha 6$ occurred, provoking the appearance of a premature stop codon at the beginning of exon 5 . Next, we observed that exons $3 \mathrm{~b}$ and 4 were not present in gDNA of Q68* isoline, while intronic region downstream of exon $3 \mathrm{a}$ and upstream of exon 5 were present, indicating that a deletion must had occurred in between of these exons. Conversely, when we checked the sequence of both the gDNA and the cDNA of isoline Q68*-K352*, we found that all exons were present and transcribed. To understand whether the deletion of exons 

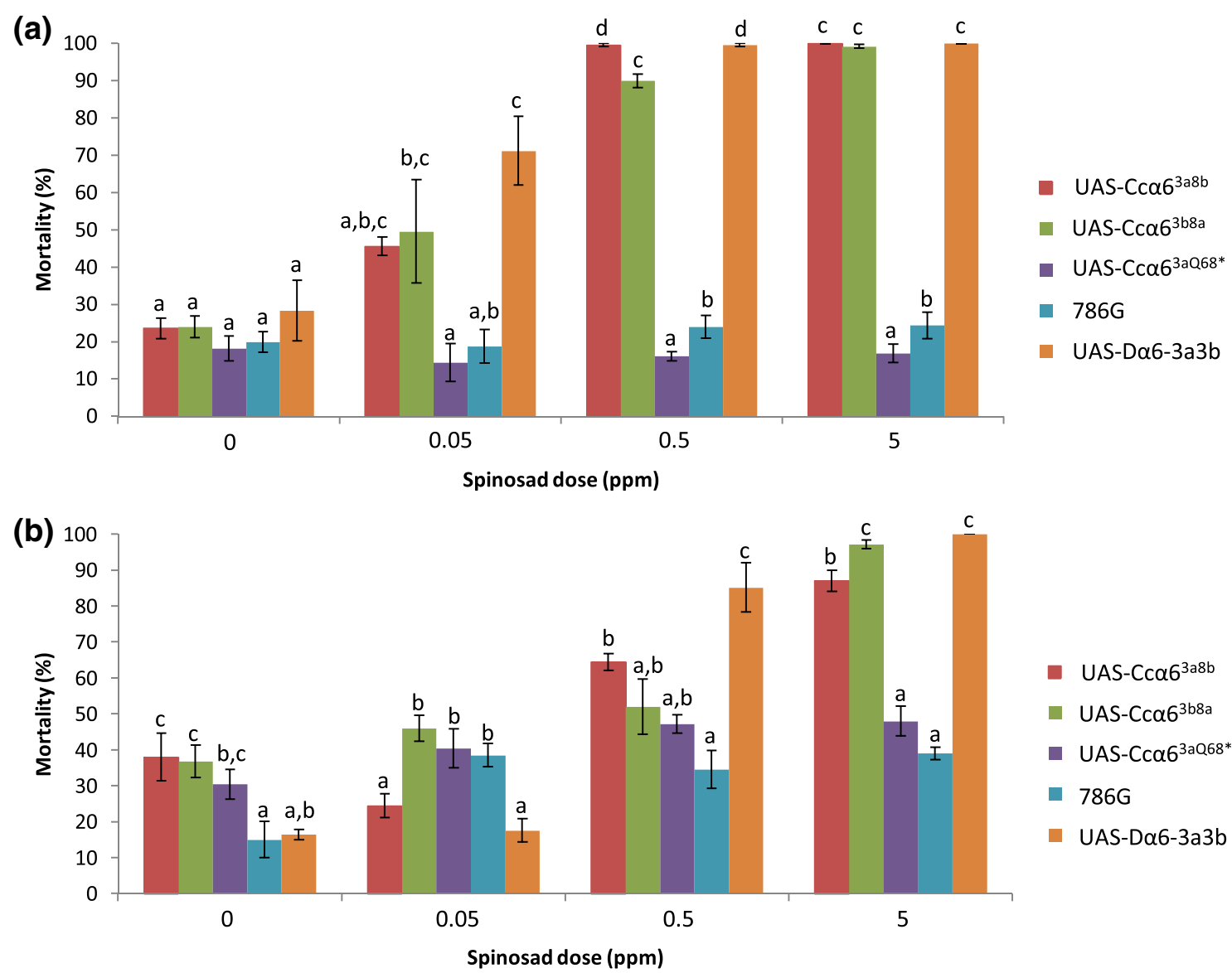

Fig. 1 Mortality percentages obtained from exposure to increasing spinosad concentrations of: a F1 transgenic Drosophila melanogaster flies coming from the cross between the D $\alpha 6>$ GAL4 and the UAS-Cc $\alpha 6$ lines $\mathrm{Cc} \alpha 6^{3 \mathrm{a} 8 \mathrm{~b}}, \mathrm{Cc} \alpha 6^{3 \mathrm{~b} 8 \mathrm{a}}, \mathrm{Cc} \alpha 6^{\mathrm{Q} 68^{*}}, 786 \mathrm{G}$ and UASD $\alpha 6-3 \mathrm{a} 3 \mathrm{~b}$ (with a susceptible nACh6 transcript); and b parental

had occurred during the generation of Q68* isoline or whether it was already present in JW-100s, we checked the gDNA and cDNA of JW-100s individuals carrying the allele $C c \alpha 6^{3 a Q 68 *}$ of generations F29 (30\% of individuals homozygous $\left.C c \alpha 6^{3 a Q 68 *} / C c \alpha 6^{3 a Q 68 *}\right)$ and F85 (92\% of individuals homozygous $C c \alpha 6^{3 a Q 68 *-K 352 *} / C c \alpha 6^{3 a Q 68^{*}-K 352 *}$ and just $8 \%$ of individuals heterozygous $\left.C c \alpha 6^{3 a Q 68 *} / C c \alpha 6^{3 a Q 68^{*}-K 352 *}\right)$. We found that $C c \alpha 6^{3 a Q 68^{*}}$ allele carried all exons in F29, while exons $3 \mathrm{~b}$ and 4 were absent in $\mathrm{F} 85$, suggesting that the deletion happened at an unknown generation during the selection of JW-100s strain in the laboratory. Furthermore, qPCR analysis to test the expression of exons $3 \mathrm{a}$ and $3 \mathrm{~b}$ in Q68* and Q68*-K352* isolines confirmed that exons $3 \mathrm{~b}$ and 4 were not expressed in Q68* (Fig. 2). The results also indicated that expression of both $3 \mathrm{a}$ and $3 \mathrm{~b}$ exons was significantly lower in Q68*-K352* isoline than in C strain (Fig. 2). The compendium of results of sequence and expression of $C c \alpha 6$ allowed to elucidate that $C c \alpha 6^{3 a Q 68^{*}}$ allele had lost exons $3 \mathrm{~b}$ and 4 during the selection of JW-100s giving
UAS-Cc $\alpha 6$ lines of D. melanogaster flies. All flies used in the crosses were homozygous for the $d \alpha 6^{n x}$ allele (no D $\alpha 6$ expression). Different letters within each concentration indicate significant differences (ANOVA, Student-Newman-Keuls post hoc test, $p \leq 0.05$. Data were previously arcsin transformed)

rise to a new allele $C c \alpha 6^{3 a Q 68 * \Delta 3 b-4}$, which gives rise to isoforms that truncate at exon $3 \mathrm{a}$, and to isoforms lacking exons $3 \mathrm{~b}$ and 4 that truncate at exon 5 (Fig. 3). On the other hand, Q68*-K352* isoline kept the allele $C c \alpha 6^{3 a Q 68 *-K 352 *}$ as originally was in JW-100s strain, though the expression of both $3 \mathrm{a}$ and $3 \mathrm{~b}$ isoforms was reduced when compared to the $\mathrm{C}$ strain.

We performed bioassays on the isolines in order to compare the levels of resistance in them with that reported for JW-100s. Feeding spinosad at the concentration used in field treatments (260 ppm in bait sprays) did not cause mortality in either isoline. Feeding bioassays could not be performed at higher concentrations because of the limited solubility of spinosad in aqueous solutions. Topical bioassays with a range of doses of spinosad (Table 1) indicated that both Q68* and Q68*-K352* isolines had similar levels of resistance, with resistance ratios (RR) of 3139 and 3602, respectively, when compared to the susceptible $\mathrm{C}$ strain. These data 


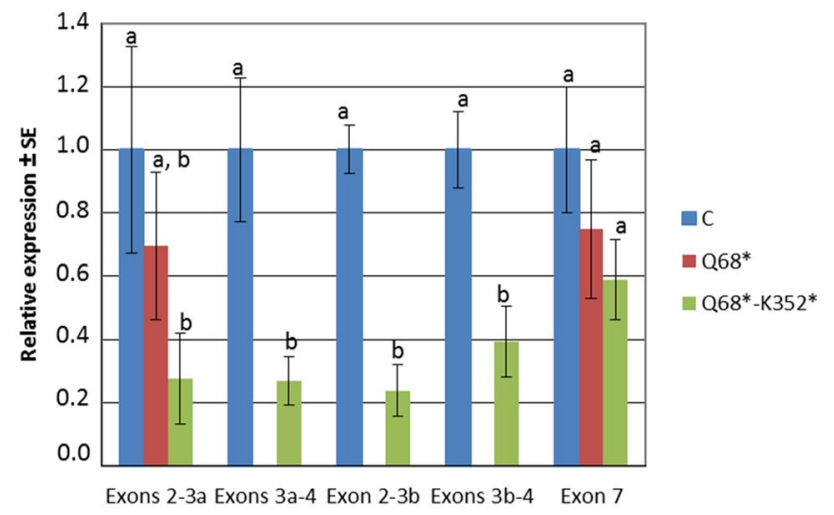

Fig. 2 Expression of Cc $\alpha 6$ gene in C strain, and Q68* and Q68*$\mathrm{K} 352 *$ isolines of Ceratitis capitata. Oligonucleotides were designed for the exonic regions: $2-3 a, 3 a-4,3 b$ and 7 . Data are mean \pm standard error of three pools of six individuals normalized to the reference genes actin, glycerol-3-phosphate dehydrogenase (GPDH) and $\alpha$-tubulin, and relative to $\mathrm{C}$ strain. Different letters within each exonic region indicate significant differences (exonic regions $3 a-4,2-3 b$, 3b-4: Student's $t$ test; exonic regions 2-3a and 7: ANOVA, StudentNewman-Keuls post hoc test, $p \leq 0.05$ )

indicate that both alleles contribute equally to the resistant phenotype of JW-100s ( $R R=1794$, Ureña et al. 2019).

\section{Stability of spinosad-resistant alleles $C \mathrm{Ca} 6^{3 a Q 68^{*}-K 352^{*}}$ and $C c a 6^{3 a Q 68^{*} \triangle 3 b-4}$ in C. capitata}

In order to study the stability of $C c \alpha 6^{3 a Q 68^{*-K 352 *}}$ and $C c \alpha 6^{3 a Q 68^{*} \Delta 3 b-4}$ alleles in C. capitata, we performed crosses among Q68* and Q68*-K352* isolines and C strain to obtain individuals heterozygous for one of the resistant alleles and the wild-type $C c \alpha 6^{+}$allele or heterozygous for both resistant alleles. We then followed the frequency of the different genotypes in the successive generations.

The fate of the different $C c \alpha 6$ alleles depended on the crosses performed (Table 2). In QC and $\mathrm{KC}$ crosses that carried only one of the resistant alleles $\left(C c \alpha 6^{3 a Q 68^{*} \Delta 3 b-4}\right.$ or $\left.C c \alpha 6^{3 a Q 68^{*}-K 352 *}\right)$ and the wild-type allele $\left(C c \alpha 6^{+}\right)$, the genotypic frequencies obtained in G1 corresponded to those expected under Mendelian inheritance (25\% homozygous wild-type, $50 \%$ heterozygous and $25 \%$ homozygous resistant). After this, we observed a rapid and continuous decline in the frequency of homozygous-resistant genotypes, not observed after G7. Heterozygous individuals remained at low frequency after nine generations. On the other hand, when both $C c \alpha 6^{3 a Q 68^{*}-K 352^{*}}$ and $C c \alpha 6^{3 a Q 68^{*} \Delta 3 b-4}$ alleles coexisted in the QK cross, the typical frequencies of the Mendelian inheritance were maintained in Hardy-Weinberg equilibrium until the end of the experiment (G9), in both untreated and spinosad selected conditions. This result indicates that $C c \alpha 6^{3 a Q 68 * \Delta 3 b-4}$ and $C c \alpha 6^{3 a Q 68^{*-K 352 *}}$ resistant alleles have a fitness cost compared to the wild-type allele, and that it is higher in homozygosis than in heterozygosis. However, no difference in fitness cost was observed between both strains.

\section{Fitness of Q68* and Q68*-K352* isolines of C. capitata}

We analyzed biological and behavioral traits in the Q68* and Q68*-K352* isolines of $C$. capitata and compared them to $\mathrm{C}$ strain in order to associate the existence of any fitness cost with the presence of a mutant allele conferring resistance.

\section{Biological traits}

We compared the embryo to pupal viability of the isolines and the $\mathrm{C}$ strain by analyzing the number of pupae obtained from a volume of $50 \mu \mathrm{l}$ of eggs. No significant differences were observed (Table 3). The analysis of embryo to pupa development time showed that Q68* isoline developed significantly slower than C strain, with the Q68*-K352* isoline developing even slower (Table 3). We also checked if there were differences in adult weight between these genotypes. It was equivalent for females of all strains (Table 3 ), but males from the resistant Q68* and Q68*-K352* isolines were significantly heavier than those from the susceptible $\mathrm{C}$ strain.

\section{Behavioral traits}

We performed a wind tunnel assay to study the ability of male flies of $C$. capitata to get attracted by the synthetic parapheromone, trimedlure. We saw that males from Q68* isoline had a lower response to trimedlure than males from $\mathrm{C}$ strain and Q68*-K352* isoline, when considered the percentage of males responding to trimedlure during an exposition of $30 \mathrm{~min}$ (Fig. 4a) and the time needed by the first fly to reach the parapheromone (Fig. 4b). On the contrary, the ability of males of Q68*-K352* isoline to respond to the parapheromone resulted similar to that of the wild type.

We also carried out an EAG assay to analyze whether males' antennal receptors were able to detect the parapheromone trimedlure. Among all the concentrations tested, we observed significant differences only with a dose of $5 \mathrm{ng}$ of trimedlure, where the response in Q68*-K352* was higher than in the $\mathrm{C}$ males (Fig. 5). We did not observe any significant difference between Q68* and C strain at any of the concentrations tested.

We conducted competitive mating assays to find out whether there were differences in fecundation success when males of the different strain/isolines were put together with a group of females of a specific strain/isoline. We did not observe significant differences in the number of fecundated females when females belonged to C strain or Q68* isoline. 
(a) C strain

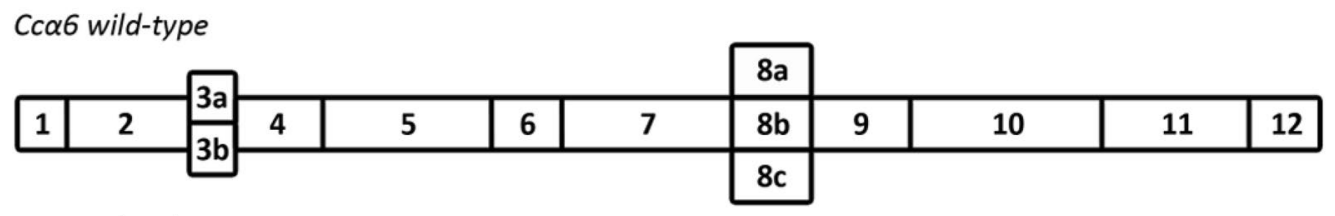

(b) JW-100s strain (F29)

$C c \alpha 6^{3 a Q 68^{*}-K 352^{*}}$

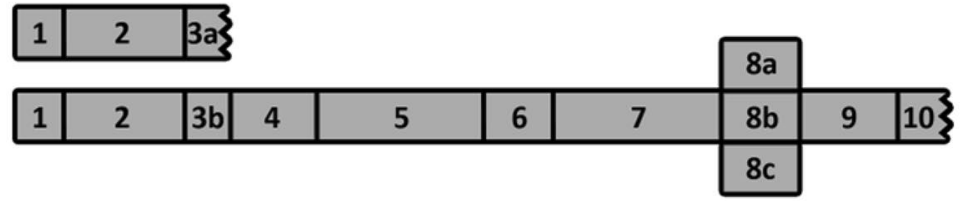

$C c \alpha 6^{3 a Q 68^{*}}$

\begin{tabular}{|l|l|l|l|l|l|l|l|l|l|l|l|}
\hline 1 & 2 & $3 a 3$ & $8 \mathrm{a}$ & \multicolumn{1}{|c|}{} \\
\hline 1 & 2 & $3 \mathrm{~b}$ & 4 & 5 & 6 & 7 & $8 \mathrm{~b}$ & 9 & 10 & 11 & 12 \\
\hline
\end{tabular}

(c) Q68* isoline

$C c \alpha 6^{3 a Q 68^{*} \Delta 3 b-4}$

\begin{tabular}{|l|l|l|}
\hline 1 & 2 & 3 a3 \\
\hline
\end{tabular}

\begin{tabular}{|l|l|l|}
\hline 1 & 2 & 5 \\
\hline
\end{tabular}

(d) Q68*-K352* isoline

$C c \alpha 6^{3 a Q 68^{*}-K 352^{*}}$

\begin{tabular}{|l|l|l|}
\hline 1 & 2 & 3 a3 \\
\hline
\end{tabular}

\begin{tabular}{|l|l|l|l|l|l|l|l|l|l|}
\hline 1 & 2 & $3 b$ & 4 & 5 & 6 & 7 & $8 b$ & 9 & 103 \\
\hline
\end{tabular}

Fig. 3 Cc $\alpha 6$ gene structure and its mRNA isoforms in: a C strain; b JW-100s strain at generation F29; c Q68* isoline and d Q68*-K352* isolines of Ceratitis capitata. Dark gray structures are truncated iso- forms carrying stop codons, light gray means isoforms lacking some exons, and white refers to non-truncated isoforms. Sections $\mathbf{a}$ and $\mathbf{b}$ have been extracted from Ureña et al. (2019)
However, Q68*-K352* males were more successful in fecundating Q68*-K352* females than Q68*males (Fig. 6).

The results of the wind tunnel, the EAG and the mating assays indicate that males carrying the $C c \alpha 6^{3 a Q 68 * \Delta 3 b-4}$ allele have impaired ability to detect the parapheromone and to mate females carrying the $C c \alpha 6^{3 a Q 68^{*}-K 352^{*}}$ allele.

\section{Discussion}

In a previous study, it was shown that medflies homozygous for $C c \alpha 6^{3 a Q 68^{*}}$ allele were resistant to spinosad, despite generating wild-type full-length $C c \alpha 6$ isoforms with exon $3 \mathrm{~b}$
(Ureña et al. 2019). Here, we have used the GAL4 > UAS expression system to introduce in D. melanogaster $d \alpha 6$ lossof-function mutants three different $C c \alpha 6$ isoforms: (1) the isoform carrying $3 \mathrm{aQ} 68^{*}$ mutation, encoded by $C c \alpha 6^{3 a Q 68^{*}}$ allele; (2) the wild-type mRNA isoform $3 \mathrm{~b} 8 \mathrm{a}$, encoded by both $C c \alpha 6^{3 a Q 68^{*}}$ and $C c \alpha 6^{+}$alleles; and (3) the wild-type mRNA isoform $3 \mathrm{a} 8 \mathrm{~b}$, encoded by $C c \alpha \sigma^{+}$allele. As expected, the expression of the isoform carrying mutation $3 \mathrm{aQ68*}$ does not rescue susceptibility to spinosad, confirming that the truncated transcripts do not produce a response to spinosad (Baxter et al. 2010; Rinkevich et al. 2010; Hsu et al. 2012). On the contrary, we found that the expression of both wild-type $C c \alpha 6^{3 a 8 b}$ and $C c \alpha 6^{3 b 8 a}$ isoforms rescued spinosad 
Table 1 Resistance levels to spinosad of JW-100s and C strains and Q68* and Q68*_ K352* isolines of Ceratitis capitata

\begin{tabular}{lllllll}
\hline Isoline/strain & $\mathrm{N}^{(1)}$ & Slope \pm S.E. & $\mathrm{LD}_{50}^{(2)}(95 \% \mathrm{FL})$ & $\chi^{2(3)}$ & D.f. & $\mathrm{RR}(95 \% \mathrm{FL})^{(4)}$ \\
\hline JW-100s $^{(5)}$ & 419 & $4.74 \pm 0.61$ & $185(142-224)$ & 83.7 & 22 & $1794(1156-2785) \#$ \\
Q68*-K352* $^{*}$ & 390 & $2.26 \pm 0.30$ & $371(284-483)$ & 35.3 & 21 & $3602(2253-5757) \#$ \\
Q68* & 390 & $3.59 \pm 0.45$ & $323(266-378)$ & $26.6^{*}$ & 21 & $3139(2000-4927) \#$ \\
$\mathrm{C}$ & 306 & $2.34 \pm 0.67$ & $0.10(0.08-0.18)$ & $15.6^{*}$ & 18 & 1 \\
\hline
\end{tabular}

${ }^{(1)}$ Number of flies considered in the Probit analysis (including non-treated)

${ }^{(2)}$ Lethal dose $\left(\mathrm{LD}_{50}\right)$ in $\mu \mathrm{g} / \mathrm{g}$ of insect (fresh weight assuming an average weight of $10 \mathrm{mg}$ ) for topical assays at $48 \mathrm{~h}$ performed with spinosad $88 \%$ technical grade insecticide (a $0.5 \mu \mathrm{l}$ drop of insecticide solution in acetone or acetone alone was applied to the dorsal thorax of each fly by using an automatic microapplicator)

${ }^{(3)}$ Good fit $(*)$ of the data to the Probit model $(P>0.05)$

${ }^{(4)}$ Resistance ratio $(\mathrm{RR})=\left[\mathrm{LD}_{50}\right.$ (selected strain) $/ \mathrm{LD}_{50}(\mathrm{C}$ strain) $]$. The fiducial limits for $\mathrm{RR}$ were calculated according to Robertson and Preisler (1992). " RR is significant $(P<0.05)$ if the 95\% FL does not include 1

${ }^{(5)}$ Data from Ureña et al. (2019) susceptibility in the $\alpha 6$-deficient strain, as already reported for D $\alpha 6$ isoforms from susceptible D. melanogaster strains and of orthologues from susceptible strains of a variety of species (Perry et al. 2011, 2015; Anstead et al. 2015). Ureña et al. (2019) hypothesized that the absence of wild-type isoforms containing exon $3 \mathrm{a}$ in individuals homozygous for $C c \alpha 6^{3 a Q 68^{*}}$ allele could be enough to confer resistance to spinosad in medfly, since it has been suggested that some isoforms could be more responsive to spinosad or better able to form functional receptors than others (Perry et al. 2015). However, our results indicate that medfly $3 \mathrm{~b} 8 \mathrm{a}$ isoform is enough to mediate spinosad toxicity. We must keep in mind the fact that the GAL4 > UAS system usually confers higher expression levels than that observed under native conditions, which could mean that the susceptible phenotype observed could be due to $3 \mathrm{~b} 8 \mathrm{a}$ isoform being expressed at abnormally high, non-physiological levels. Nonetheless, we have found that UAS-Cc $\alpha 6^{3 \mathrm{~b} 8 \mathrm{a}}$ construct in the absence of GAL4 driver is sufficient to partially rescue the susceptibility to spinosad, as also observed with UAS-Cc $\alpha 6^{3 \mathrm{a} 8 \mathrm{~b}}$, which suggests that basal expression of both isoforms is enough for spinosad to be toxic, as observed previously (Perry et al. 2015). Alternative explanations for resistance conferred by $C c \alpha 6^{3 a Q 68^{*}}$ allele, despite the expression of susceptible $3 \mathrm{~b}$ isoforms, have been proposed: i) that truncated $3 \mathrm{a}$ isoforms may interfere with the correct assembly of $\mathrm{nAChR}$ receptors in medfly and ii) the presence of undetected mutations in non-coding regions that could affect the transcript stability or the translation of full-length wild-type $3 \mathrm{~b}$ isoforms (Ureña et al. 2019). Further studies are required to prove whether the $3 \mathrm{~b} 8 \mathrm{a}$ isoform encoded by the $C \operatorname{co} \alpha 6^{3 \mathrm{a} Q 68^{*}}$ allele has affected its functionality in medfly.

Remarkably, when we tried to obtain an isoline homozygous for the $C \operatorname{co} \alpha 6^{3 a Q 68^{*}}$ allele, we realized that the resulting Q68* isoline was homozygous for a new $C c \alpha 6^{3 a Q 68 * \Delta 3 b-4}$ allele composed by isoforms that truncate at exon $3 \mathrm{a}$ and isoforms lacking exons $3 \mathrm{~b}$ and 4 as a consequence of a deletion in the gDNA that truncate in exon 5 (Fig. 3). We confirmed that the allele $C \operatorname{co} \alpha 6^{3 a Q 68^{*}}$ expressing full-length wild-type $3 \mathrm{~b}$ isoforms was present in JW-100s individuals from generation F29, as already reported (Ureña et al. 2019). However, we found that heterozygous $C c \alpha 6^{3 a Q 68^{*} \Delta 3 b-4}$ / $C c \alpha 6^{3 a Q 68^{*}-K 352^{*}}$ individuals of JW-100s strain from generation $\mathrm{F} 85$, about ten generations previous to the parents that were used to generate the Q68* isoline, already lacked exons $3 \mathrm{~b}$ and 4 . Thus, $C c \alpha 6^{3 a Q 68 * \Delta 3 b-4}$ allele might have appeared at an undetermined point during the selection of JW-100s with spinosad. It is probable that this new allele had been generated from $C c \alpha 6^{3 a Q 68^{*}}$. Nevertheless, we cannot discard that $C c \alpha 6^{3 a Q 68 * \Delta 3 b-4}$ was already present at very low frequency in JW-100s. Regardless of its origin, it could have been selected instead of $C \operatorname{co} \alpha 6^{3 a Q 68^{*}}$ because of better stability or lower fitness cost. Insect $n A C h R$ subunit genes have a complex process of splicing, and different isoforms are usually expressed in natural conditions (Sattelle et al. 2005). Indeed, the existence of $n A C h R$ transcripts lacking some exons appears to be common in insects (Jones et al. 2006). This includes $\alpha 6$ transcripts missing both forms of exon 3 that have been identified at low proportion in wildtype populations of Bombyx mori, Tribolium castaneum, $T$. absoluta and P. xylostella (Shao et al. 2007; Rinkevich and Scott 2009; Berger et al. 2016; Wang et al. 2016). Indeed, Berger et al. (2016) reported that spinosad resistance in $T$. absoluta was associated with altered nAChR $\alpha 6$ transcripts that lacked exon $3 \mathrm{a} / 3 \mathrm{~b}$, though in this case, both exons were present and unaltered at the genomic level, indicating that their absence in mRNA results from exon skipping rather than a deletion in gDNA. It is not known whether nAChR transcripts with stop codons and/or exclusion of exons are translated, and if so, the functional role of the resulting proteins, though some regulatory and modulatory roles have been proposed (Sattelle et al. 2005). In any case, our 
Table 2 Genotype frequencies (\%) in the progeny of the crosses between Q68* and Q68*-K352* isolines and C strain of Ceratitis capitata

\begin{tabular}{|c|c|c|c|c|c|}
\hline \multirow{2}{*}{$\begin{array}{l}\text { Crosses }^{(1)} \\
\text { Q68*×Q68*-K352*(QK) }\end{array}$} & \multirow{2}{*}{ Generation } & \multicolumn{3}{|c|}{ Genotypes $(\overline{\mathrm{X}} \pm \mathrm{SE})^{(2)}$} & \multirow[t]{2}{*}{$\begin{array}{l}\text { Fit the model } \\
(\text { Chi-square test })^{(3)}\end{array}$} \\
\hline & & $\begin{array}{l}\mathrm{Cc} \alpha 6^{3 \mathrm{aQQ} 68^{*} \Delta 3 b-4} / \\
\mathrm{Cc} \alpha 6^{3 \mathrm{a}} \mathrm{Q} 68^{*} \Delta 3 b-4\end{array}$ & $\begin{array}{l}\mathrm{Cc} \alpha 6^{3 \mathrm{a} \mathrm{Q} 68^{*} \Delta 3 b-4} / \\
\mathrm{Cc} \alpha 6^{3 \mathrm{a}} \mathrm{Q} 68^{*}-K 352^{*}\end{array}$ & $\begin{array}{c}\mathrm{Cc} \alpha 6^{3 \mathrm{a}} \mathrm{Q} 68^{*-K 352 *} / \\
\mathrm{Cc} \alpha 6^{3 \mathrm{a}} \mathrm{Q} 68^{*}-K 352^{*}\end{array}$ & \\
\hline & $Q K n t$ & & & & \\
\hline & G0 & $0 \pm 0$ & $100 \pm 0$ & $0 \pm 0$ & $*$ \\
\hline & G1 & $40.8 \pm 3.8$ & $50.9 \pm 4.7$ & $8.3 \pm 8.3$ & \\
\hline & G3 & $16.7 \pm 4.2$ & $66.7 \pm 4.2$ & $16.7 \pm 4.2$ & $*$ \\
\hline & G5 & $46.7 \pm 3.3$ & $33.3 \pm 8.8$ & $20 \pm 11.6$ & \\
\hline & G7 & $20 \pm 5.8$ & $46.7 \pm 3.3$ & $33.3 \pm 3.3$ & $*$ \\
\hline & G9 & $30 \pm 5.8$ & $56.7 \pm 12$ & $13.3 \pm 6.7$ & $*$ \\
\hline & $Q K s$ & & & & \\
\hline & G3 & $25 \pm 12.5$ & $58.3 \pm 18.2$ & $16.7 \pm 8.3$ & $*$ \\
\hline & G5 & $23.3 \pm 3.3$ & $36.7 \pm 8.8$ & $40 \pm 5.8$ & $*$ \\
\hline & G7 & $40 \pm 10$ & $36.7 \pm 6.7$ & $23.3 \pm 14.5$ & $*$ \\
\hline & G9 & $40 \pm 10$ & $46.7 \pm 8.8$ & $13.3 \pm 3.3$ & $*$ \\
\hline \multirow[t]{7}{*}{$\mathrm{Q} 68^{*} \times \mathrm{C}(\mathrm{QC})$} & & $\mathrm{Cc} \alpha 6^{+} / \mathrm{Cc} \alpha 6^{+}$ & $\mathrm{Cc} \alpha 6^{3 \mathrm{a} Q 68 *} / \mathrm{Cc} \alpha 6^{+}$ & $\begin{array}{c}\mathrm{Cc} \alpha 6^{3 \mathrm{aQ} 68^{*} \Delta 3 b-4} / \\
\mathrm{Cc} \alpha 6^{3 \mathrm{a}} \mathrm{Q} 68^{*} \Delta 3 b-4\end{array}$ & \\
\hline & G0 & $0 \pm 0$ & $100 \pm 0$ & $0 \pm 0$ & \\
\hline & G1 & $34.4 \pm 3.6$ & $52.6 \pm 4.6$ & $13 \pm 5$ & \\
\hline & G3 & $54.2 \pm 10.5$ & $45.8 \pm 10.5$ & $0 \pm 0$ & \\
\hline & G5 & $55.6 \pm 13.6$ & $39.7 \pm 8.8$ & $4.8 \pm 4.8$ & \\
\hline & G7 & $75.4 \pm 17$ & $24.6 \pm 17$ & $0 \pm 0$ & \\
\hline & G9 & $70.6 \pm 7.6$ & $29.4 \pm 7.6$ & $0 \pm 0$ & \\
\hline \multirow[t]{7}{*}{$\mathrm{Q} 68 *-\mathrm{K} 352 * \times \mathrm{C}(\mathrm{KC})$} & & $\mathrm{Cc} \alpha 6^{+} / \mathrm{Cc} \alpha 6^{+}$ & $\mathrm{Cc} \alpha 6^{3 \mathrm{a} Q 68^{*}-K 352^{*}} / \mathrm{Cc} \alpha 6^{+}$ & $\begin{array}{c}\mathrm{Cc} \alpha 6^{3 \mathrm{aQQ} 68^{*}-\mathrm{K} 352 *} \\
\mathrm{Cc} \alpha 6^{3 \mathrm{a}} \mathrm{Q} 68^{*}-K 352^{*}\end{array}$ & \\
\hline & G0 & $0 \pm 0$ & $100 \pm 0$ & $0 \pm 0$ & \\
\hline & G1 & $23.3 \pm 18.6$ & $60 \pm 17.3$ & $16.7 \pm 12$ & \\
\hline & G3 & $58.3 \pm 15$ & $33.3 \pm 18.2$ & $8.3 \pm 4.2$ & \\
\hline & G5 & $52.2 \pm 7.8$ & $42.2 \pm 2.2$ & $5.6 \pm 5.6$ & \\
\hline & G7 & $75 \pm 25$ & $25 \pm 25$ & 0 & \\
\hline & G9 & $80 \pm 10$ & $20 \pm 10$ & 0 & \\
\hline
\end{tabular}

${ }^{(1)}$ Individuals of the Q68* and Q68*-K352* isolines were crossed among them $(\mathrm{QK})$ and with individuals of the $\mathrm{C}$ strain $(\mathrm{QC}$ and $\mathrm{KC}$, respectively). Both QC and KC were maintained without selection pressure for nine generations. QK was split at G2 in two different populations: one maintained without selection pressure (QKnt) and the other one selected with spinosad (QKs)

(2) There were three replicates of each cross. Between 20 and 40 flies of each cross and generation were genotyped

${ }^{(3)}$ Good fit $(*)$ of data to the expected genotypic frequencies $(0,100$ and $0 \%$ in $\mathrm{G} 0$, and 25,50 and $25 \%$ for all the other generations for first homozygous, heterozygous and second homozygous, respectively). Chi-square test was performed for data analysis $(p>0.05)$

Table 3 Biological parameters of adult flies from $\mathrm{C}$ strain and Q68* and Q68*-K352* isolines of Ceratitis capitata

\begin{tabular}{lccr}
\hline & C & Q68* & Q68*-K352* \\
\hline Number of pupae $^{(1)}$ & $878 \pm 102$ (a) & $755 \pm 52$ (a) & $909 \pm 45$ (a) \\
Days from egg to pupae $^{(2)}$ & $8.77 \pm 0.01$ (a) & $9.3 \pm 0.01(\mathrm{~b})$ & $9.46 \pm 0.01$ (c) \\
${\text { Females' weight }(\mathrm{g})^{(3)}}^{(3)}$ & $8.27 \pm 0.14(\mathrm{a})$ & $8.6 \pm 0.15(\mathrm{a})$ & $8.5 \pm 0.15$ (a) \\
${\text { Males' weight }(\mathrm{g})^{(3)}}$ & $7.34 \pm 0.11$ (a) & $8.29 \pm 0.15$ (b) & $7.95 \pm 0.13$ (b) \\
\hline
\end{tabular}

${ }^{(1)}$ Number of pupae obtained from a volume of eggs of $50 \mu$ l. Three replicates were performed with each strain/isoline

${ }^{(2)} n=$ number of pupae obtained for each strain/isoline in the table

${ }^{(3)} n=50$ adults $2-3$ days old

Data are mean \pm standard error. Different letters within each row indicate significant differences (ANOVA, Student-Newman-Keuls post hoc test, $p \leq 0.05$ ) 
(a)

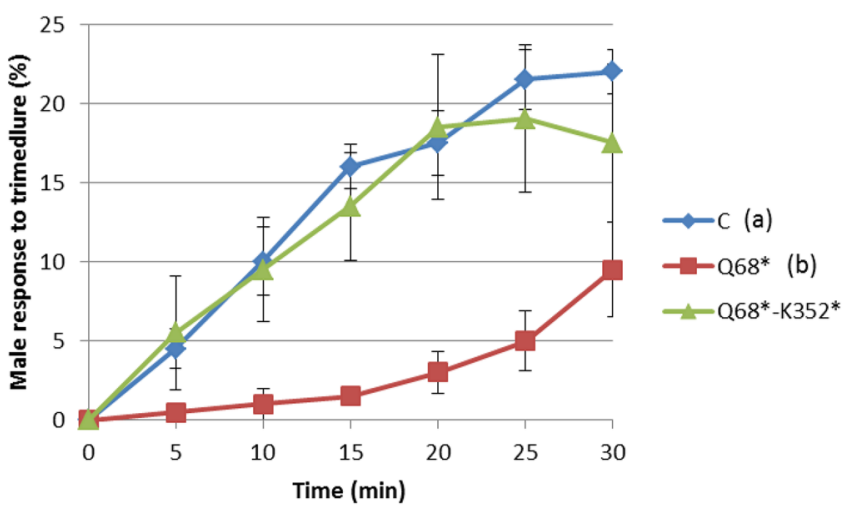

(b)

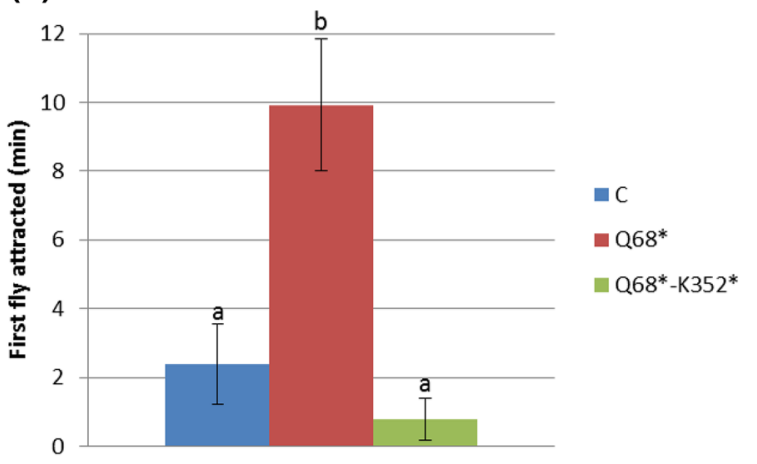

Fig. 4 Wind tunnel assay with males of $\mathrm{C}$ strain and Q68* and Q68*-K352* isolines of Ceratitis capitata; a percentage of males that respond to trimedlure during $30 \mathrm{~min}$; $\mathbf{b}$ time needed by the first fly of each strain/isoline to reach the trimedlure source. Data are mean \pm standard error of four replicates with 50 adult males in each

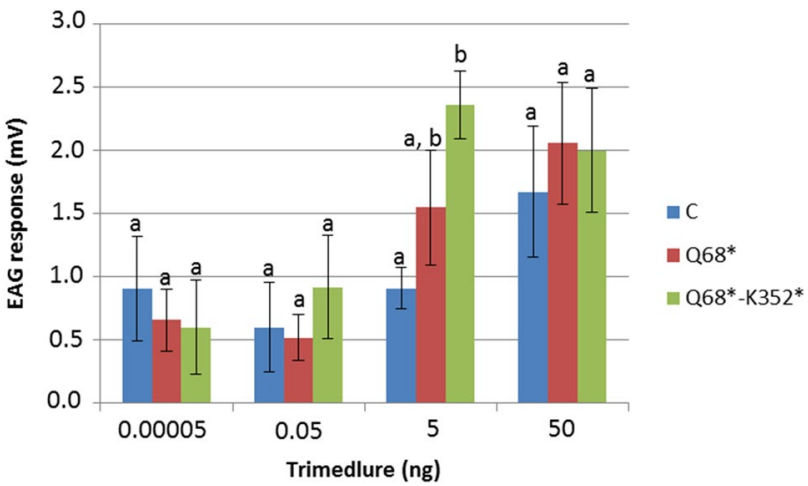

Fig. 5 Electroantennography response $(\mathrm{mV})$ of males of $\mathrm{C}$ strain and Q68* and Q68*-K352* isolines of Ceratitis capitata when exposed to increasing doses of trimedlure. Data are mean \pm standard error of 5-15 replicates. Different letters within each amount of trimedlure indicate significant differences (ANOVA, Student-Newman-Keuls post hoc test, $p \leq 0.05$ )

results and those from other studies highlight the plasticity of $\mathrm{nAChR} \alpha 6$ to generate a tremendous diversity of isoforms, including truncated isoforms potentially unaffected by spinosad.

An important factor that will determine the progress of spinosad resistance in field populations is the fitness cost of resistance. We found that both $C c \alpha 6^{3 a Q 68^{*} \Delta 3 b-4}$ and $C c \alpha 6^{3 a Q 68^{*}-K 352 *}$ alleles were not stable in the absence of spinosad when individuals from isolines homozygous for these two alleles were crossed with individuals carrying the wild-type allele $C c \alpha 6^{+}$. Our results indicate that both resistant alleles may impart a competitive disadvantage with respect to the wild-type allele. However, no differences among the stability of $C c \alpha 6^{3 a Q 68^{*} \Delta 3 b-4}$ and $C c \alpha 6^{3 a Q 68^{*}-K 352^{*}}$ one. Different letters within each row indicate significant differences (repeated measures ANOVA in male response during $30 \mathrm{~min}$ and ANOVA in first fly attracted, in both cases followed by Student-Newman-Keuls post hoc test, $p \leq 0.05$ )

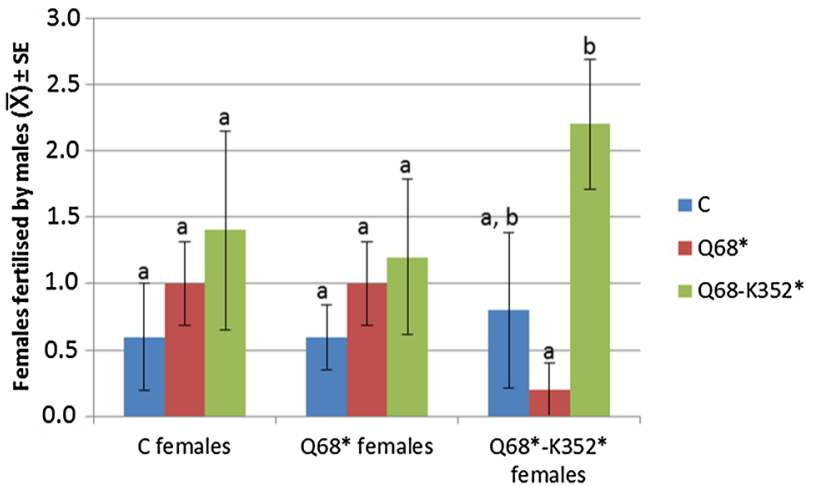

Fig. 6 Number of males of C strain and Q68* and Q68*-K352* isolines of Ceratitis capitata that, under competitive conditions, mated with females of the three strain/isolines. Data are mean \pm standard error of five replicates with ten females of a specific strain/isoline and 12 males of all strain/isolines. Different letters within each group indicate significant differences (ANOVA, Student-Newman-Keuls post hoc test, $p \leq 0.05$ )

alleles were perceived when they competed between them, both in the presence or absence of insecticide. Besides, both resistant alleles conferred similar levels of spinosad resistance, which indicated that differences in susceptibility did not play a relevant role in the competition between resistant alleles in the presence of the insecticide. Fitness cost associated with spinosad resistance has been reported to range from minor (Wyss et al. 2003) or absent (Bielza et al. 2008a; Abbas et al. 2014) to substantial (Li et al. 2007, 2017; Sayyed et al. 2008; Wang et al. 2010; Rehan and Freed 2015; Okuma et al. 2018). However, the genetic mechanism underlying spinosad resistance was only known in two of these studies, and in both cases, it was associated with 
overexpression of detoxifying enzymes (Sayyed et al. 2008; Rehan and Freed 2014). In order to identify trade-offs associated with spinosad resistance in $C$. capitata, extensive testing of both biological and behavioral traits was undertaken. We found that the effect on the biological traits tested was moderate, with Q68* $\left(C c \alpha 6^{3 a Q 68^{*} \Delta 3 b-4} / C c \alpha 6^{3 a Q 68^{*} \Delta 3 b-4}\right)$ and $\mathrm{Q} 68^{*}-\mathrm{K} 352 *\left(C c \alpha 6^{3 a Q 68^{*-K 352 *}} / C c \alpha 6^{3 a Q 68^{*}-K 352 *}\right)$ isolines showing longer developmental time but higher male weight than $\mathrm{C}$ strain, whereas females of both resistant isolines and susceptible $\mathrm{C}$ strain did not differ in weight. However, mutations that would lead to a loss-of-function phenotype may affect behavioral patterns, as it has been reported for a D $\alpha 1$ knockout mutant with a significant fitness cost in terms of severe mating behavior defects and an altered sleep phenotype (Somers et al. 2017). Thus, we explored the possibility that behavioral fitness traits (parapheromone detection by wind tunnel and electrophysiological antennal assays, and mating success) could be affected in males of the Q68* and Q68*-K352* isolines. We found that males from Q68* isoline, homozygous for $C c \alpha 6^{3 a Q 68^{*} \Delta 3 b-4}$ allele, had impaired ability to find the parapheromone source in a wind tunnel and to mate females, though EAG assays demonstrated that this impediment was not due to a failure in the response of receptors in the antennae. This could point to a failure in the flight tools to properly move inside the tunnel, or to a difficulty to orient themselves when they receive a stimulus, though further studies would be needed to confirm these hypotheses. A study focused on the competitive mating of a spinosad-resistant strain of $H$. virescens concluded that resistant adults must have a reproductive disadvantage, but they were not able to discern whether it was due to differences in mating success or in fecundity (Wyss et al. 2003). On the contrary, a homozygous $C c \alpha 6^{3 a Q 68^{*}-K 352^{*}}$ allele in the Q68*-K352* isoline does not imply a handicap for the male's ability to detect the parapheromone and to mate with females when compared to males of the $\mathrm{C}$ strain. Therefore, other fitness traits may be affected by the $C c \alpha 6^{3 a Q 68^{*}-K 352 *}$ allele that make it unstable when in competition with the wild-type allele, as it is possible that different isoforms generated by each resistant allele may interfere differently with the normal function of the receptor and with other nAChR subunits that $\alpha 6$ may also co-assemble with.

Our results highlight the plasticity of $C$. capitata to generate a wide range of mutations in $\mathrm{nAChR} \alpha 6$ that can lead to loss-of-function phenotypes potentially conferring spinosad resistance. However, these resistant alleles have a fitness cost that makes them unstable when in competition with wildtype alleles, which could be the reason for the absence of resistance events in the field (Ureña et al. 2019). In addition, the rate of resistance evolution in field populations is expected to be slow, due to the completely recessive nature of spinosad resistance in this species (Ureña et al. 2019). Nonetheless, once resistance evolved, it would be expected to increase to fixation if the selection pressure eliminated all susceptible insects. Moreover, the selection of compensatory mutations that ameliorate the fitness cost of existing resistant genotypes or the selection of less costly new resistant alleles could accelerate the evolution of resistance (Raymond et al. 2001; ffrench-Constant and Bass 2017). Thus, insect resistance management strategies should be implemented to ensure the sustainability of spinosad.

\section{Author contribution statement}

FO, PHC and LS conceived the study. FO, PHC, AGA, EU, LS, TP, PB, VN and ELE participated in the design of the experiments and the interpretation of the results. AGA, EU and ELE performed the experiments. AGA and FO wrote the first draft of the manuscript. All authors read, corrected and approved the manuscript.

Acknowledgements This work received financial support from CICYT (AGL2016-76516-R). The Spanish MINECO granted A. Guillem-Amat a predoc (BES-C-2014-068937) and a mobility (EEBB-I-16-11336) fellowships. We gratefully acknowledge María Torné (Dow Agro-Science Ibérica) for providing technical grade spinosad, Charles Robin (University of Melbourne) for assisting with bureaucratic issues with the Australian Government, Tinna Yang (University of Melbourne) for the keeping and shipping of the flies and Sandra Vacas (Universitat Politècnica de València) for the scientific advice on electroantennography.

Funding This study was funded by CICYT (Grant Number AGL2016-76516-R).

\section{Compliance with ethical standards}

Conflict of interest The authors declare that they have no conflict of interest.

Ethical approval All applicable international, national and/or institutional guidelines for the care and use of animals were followed.

Open Access This article is licensed under a Creative Commons Attribution 4.0 International License, which permits use, sharing, adaptation, distribution and reproduction in any medium or format, as long as you give appropriate credit to the original author(s) and the source, provide a link to the Creative Commons licence, and indicate if changes were made. The images or other third party material in this article are included in the article's Creative Commons licence, unless indicated otherwise in a credit line to the material. If material is not included in the article's Creative Commons licence and your intended use is not permitted by statutory regulation or exceeds the permitted use, you will need to obtain permission directly from the copyright holder. To view a copy of this licence, visit http://creativecommons.org/licenses/by/4.0/.

\section{References}

Abbas N, Mansoor MM, Shad SA et al (2014) Fitness cost and realized heritability of resistance to spinosad in Chrysoperla carnea 
(Neuroptera: Chrysopidae). Bull Entomol Res 104:707-715. https ://doi.org/10.1017/S0007485314000522

Abbott WS (1925) A method of computing the effectiveness of an insecticide. J Econ Entomol 18:265-267. https://doi.org/10.1093/ jee/18.2.265a

Anstead CA, Korhonen PK, Young ND et al (2015) Lucilia cuprina genome unlocks parasitic fly biology to underpin future interventions. Nat Commun 6:1-11. https://doi.org/10.1038/ncomms8344

Arouri R, Le Goff G, Hemden H et al (2015) Resistance to lambdacyhalothrin in Spanish field populations of Ceratitis capitata and metabolic resistance mediated by $\mathrm{P} 450$ in a resistant strain. Pest Manag Sci 71:1281-1291. https://doi.org/10.1002/ps.3924

Bao WX, Narai Y, Nakano A et al (2014) Spinosad resistance of melon thrips, Thrips palmi, is conferred by G275E mutation in $\alpha 6$ subunit of nicotinic acetylcholine receptor and cytochrome P450 detoxification. Pestic Biochem Physiol 112:51-55. https:// doi.org/10.1016/j.pestbp.2014.04.013

Baxter SW, Chen M, Dawson A et al (2010) Mis-spliced transcripts of nicotinic acetylcholine receptor $\alpha 6$ are associated with field evolved spinosad resistance in Plutella xylostella (L.). PLoS Genet. https://doi.org/10.1371/journal.pgen.1000802

Berger M, Puinean AM, Randall E et al (2016) Insecticide resistance mediated by an exon skipping event. Mol Ecol 25:5692-5704. https://doi.org/10.1111/mec.13882

Bielza P, Quinto V, Fernandez E et al (2007) Genetics of spinosad resistance in Frankliniella occidentalis (Thysanoptera: Thripidae). J Econ Entomol 100:916-920. https://doi.org/10.1603/00220493(2007)100\%5b916:gosrif\%5d2.0.co;2

Bielza P, Quinto V, Gravalos C et al (2008a) Lack of fitness costs of insecticide resistance in the western flower thrips (Thysanoptera: Thripidae). J Econ Entomol. https://doi.org/10.1603/00220493(2008)101\%5b499:lofcoi\%5d2.0.co;2

Bielza P, Quinto V, Grávalos C et al (2008b) Stability of spinosad resistance in Frankliniella occidentalis (Pergande) under laboratory conditions. Bull Entomol Res 98:355-359. https://doi. org/10.1017/S0007485308005658

Bischof J, Maeda RK, Hediger M et al (2007) An optimized transgenesis system for Drosophila using germ-line-specific C31 integrases. Proc Natl Acad Sci 104:3312-3317. https://doi.org/10.1073/ pnas.0611511104

Brand AH, Perrimon N (1993) Targeted gene expression as a means of altering cell fates and generating dominant phenotypes. Development 118:289-295. https://doi.org/10.1101/lm.1331809

Campos MR, Rodrigues ARS, Silva WM et al (2014) Spinosad and the tomato borer Tuta absoluta: a bioinsecticide, an invasive pest threat, and high insecticide resistance. PLoS ONE. https://doi. org/10.1371/journal.pone.0103235

Cossé AA, Todd JL, Millar JG et al (1995) Electroantennographic and coupled gas chromatographic-electroantennographic responses of the mediterranean fruit fly, Ceratitis capitata, to male-produced volatiles and mango odor. J Chem Ecol 21:1823-1836

Engebrecht J, Brent R, Kaderbhai MA (1991) Minipreps of plasmid DNA. Curr Protoc Mol Biol. https://doi.org/10.1002/0471142727 .mb0106s 15

Fayyazuddin A, Zaheer MA, Hiesinger PR, Bellen HJ (2006) The nicotinic acetylcholine receptor $\mathrm{Da} 7$ is required for an escape behavior in Drosophila. PLoS Biol 4:0420-0431. https://doi.org/10.1371/ journal.pbio.0040063

Ferguson JS (2004) Development and stability of insecticide resistance in the leafminer Liriomyza trifolii (Diptera: Agromyzidae) to cyromazine, abamectin, and spinosad. J Econ Entomol 97:112119. https://doi.org/10.1603/0022-0493-97.1.112

Ffrench-Constant RH, Bass C (2017) Does resistance really carry a fitness cost? Curr Opin Insect Sci 21:39-46. https://doi. org/10.1016/j.cois.2017.04.011
Geng C, Watson GB, Sparks TC (2013) Nicotinic acetylcholine receptors as spinosyn targets for insect pest management, 1st edn. Elsevier, Amsterdam

Hsu JC, Feng HT, Wu WJ et al (2012) Truncated transcripts of nicotinic acetylcholine subunit gene Bd $\alpha 6$ are associated with spinosad resistance in Bactrocera dorsalis. Insect Biochem Mol Biol 42:806-815. https://doi.org/10.1016/j.ibmb.2012.07.010

IRAC (2019) Arthropod pesticide resistance database. https://www. pesticideresistance.org/index.php. Accessed 16 May 2019

Jang EB, Light DM, Binder RG et al (1994) Attraction of female mediterranean fruit flies to the five major components of maleproduced pheromone in a laboratory flight tunnel. J Chem Ecol 20:9-20. https://doi.org/10.1007/BF02065987

Jin Y, Tian N, Cao J et al (2007) RNA editing and alternative splicing of the insect nAChR subunit alpha6 transcript: evolutionary conservation, divergence and regulation. BMC Evol Biol 7:1-12. https://doi.org/10.1186/1471-2148-7-98

Jones AK, Raymond-Delpech V, Thany SH et al (2006) The nicotinic acetylcholine receptor gene family of the honey bee, Apis mellifera. Genome Res 16:1422-1430. https://doi.org/10.1101/gr.45492 06

Khan HAA, Akram W, Shad SA (2014) Genetics, cross-resistance and mechanism of resistance to spinosad in a field strain of $\mathrm{Musca}$ domestica L. (Diptera: Muscidae). Acta Trop 130:148-154. https ://doi.org/10.1016/j.actatropica.2013.11.006

Li ZM, Liu SS, Liu YQ, Ye GY (2007) Temperature-related fitness costs of resistance to spinosad in the diamondback moth, Plutella xylostella (Lepidoptera: Plutelidae). Bull Entomol Res 97:627635. https://doi.org/10.1017/S0007485307005366

Li X, Wan Y, Yuan G et al (2017) Fitness trade-off associated with spinosad resistance in Frankliniella occidentalis (Thysanoptera: Thripidae). J Econ Entomol 110:1755-1763. https://doi. org/10.1093/jee/tox 122

Magaña C, Hernandez-Crespo P, Ortego F, Castañera P (2007) Resistance to malathion in field populations of Ceratitis capitata. $\mathrm{J}$ Econ Entomol 100:1836-1843. https://doi.org/10.1603/00220493(2007)100\%5b1836:rtmifp\%5d2.0.co;2

Magaña C, Hernández-Crespo P, Brun-Barale A et al (2008) Mechanisms of resistance to malathion in the medfly Ceratitis capitata. Insect Biochem Mol Biol 38:756-762. https://doi.org/10.1016/j. ibmb.2008.05.001

MAPA (2019) Ministerio de Agricultura, Pesca y Alimentación. https ://www.mapa.gob.es/es/. Accessed 12 Jun 2019

Navarro-Llopis V, Primo J, Vacas S (2015) Bait station devices can improve mass trapping performance for the control of the Mediterranean fruit fly. Pest Manag Sci 71:923-927. https://doi. org/10.1002/ps.3864

Okuma DM, Bernardi D, Horikoshi RJ et al (2018) Inheritance and fitness costs of Spodoptera frugiperda (Lepidoptera: Noctuidae) resistance to spinosad in Brazil. Pest Manag Sci 74:1441-1448. https://doi.org/10.1002/ps.4829

Perry T, Batterham P (2018) Harnessing model organisms to study insecticide resistance. Curr Opin Insect Sci 27:61-67. https://doi. org/10.1016/j.cois.2018.03.005

Perry T, McKenzie JA, Batterham P (2007) A D $\alpha 6$ knockout strain of Drosophila melanogaster confers a high level of resistance to spinosad. Insect Biochem Mol Biol 37:184-188. https://doi. org/10.1016/j.ibmb.2006.11.009

Perry T, Batterham P, Daborn PJ (2011) The biology of insecticidal activity and resistance. Insect Biochem Mol Biol 41:411-422. https://doi.org/10.1016/j.ibmb.2011.03.003

Perry T, Somers J, Yang YT, Batterham P (2015) Expression of insect $\alpha 6$-like nicotinic acetylcholine receptors in Drosophila melanogaster highlights a high level of conservation of the receptor: 
spinosyn interaction. Insect Biochem Mol Biol 64:106-115. https ://doi.org/10.1016/j.ibmb.2015.01.017

Puinean AM, Lansdell SJ, Collins T et al (2013) A nicotinic acetylcholine receptor transmembrane point mutation $(\mathrm{G} 275 \mathrm{E})$ associated with resistance to spinosad in Frankliniella occidentalis. J Neurochem 124:590-601. https://doi.org/10.1111/jnc.12029

Raymond M, Berticat C, Weill M et al (2001) Insecticide resistance in the mosquito Culex pipiens: what have we learned about adaptation? Genetica 112-113:287-296. https://doi. org/10.1023/A:1013300108134

Reddy PVR, Rashmi MA (2016) Sterile insect technique (SIT) as a component of area-wide integrated management of fruit flies: status and scope. Pest Manag Hortic Ecosyst 22:1-11. https:// doi.org/10.1097/01.ede.0000100289.82156.8b

Rehan A, Freed S (2014) Selection, mechanism, cross resistance and stability of spinosad resistance in Spodoptera litura (Fabricius) (Lepidoptera: Noctuidae). Crop Prot 56:10-15. https://doi. org/10.1016/j.cropro.2013.10.013

Rehan A, Freed S (2015) Fitness cost of methoxyfenozide and the effects of its sublethal doses on development, reproduction, and survival of spodoptera litura (Fabricius) (Lepidoptera: Noctuidae). Neotrop Entomol 44:513-520. https://doi.org/10.1007/s1374 4-015-0306-5

Rinkevich FD, Scott JG (2009) Transcriptional diversity and allelic variation in nicotinic acetylcholine receptor subunits of the red flour beetle, Tribolium castaneum. Insect Mol Biol 18:233-242. https://doi.org/10.1111/j.1365-2583.2009.00873.x

Rinkevich FD, Chen M, Shelton AM, Scott JG (2010) Transcripts of the nicotinic acetylcholine receptor subunit gene Pxyla6 with premature stop codons are associated with spinosad resistance in diamondback moth, Plutella xylostella. Invertebr Neurosci 10:25-33. https://doi.org/10.1007/s10158-010-0102-1

Robertson JL, Preisler HK (1992) Pesticide bioassays with arthropods. CRC Press, Boca Raton

Salgado VL, Sparks TC (2005) 6.5-the spinosyns: chemistry, biochemistry, mode of action, and resistance. In: Comprehensive molecular insect science. pp 137-173

Sattelle DB, Jones AK, Sattelle BM et al (2005) Edit, cut and paste in the nicotinic acetylcholine receptor gene family of Drosophila melanogaster. BioEssays 27:366-376. https://doi.org/10.1002/ bies. 20207

Sayyed AH, Saeed S, Noor-Ul-Ane M, Crickmore N (2008) Genetic, biochemical, and physiological characterization of spinosad resistance in Plutella xylostella (Lepidoptera: Plutellidae). J Econ Entomol 101:1658-1666. https://doi.org/10.1603/0022-0493

Shao YM, Dong K, Zhang CX (2007) The nicotinic acetylcholine receptor gene family of the silkworm, Bombyx mori. BMC Genom 8:1-10. https://doi.org/10.1186/1471-2164-8-324

Shi M, Yue Z, Kuryatov A et al (2014) Identification of redeye, a new sleep-regulating protein whose expression is modulated by sleep amount. Elife 2014:1-17. https://doi.org/10.7554/eLife.01473
Silva WM, Berger M, Bass C et al (2016) Mutation (G275E) of the nicotinic acetylcholine receptor $\alpha 6$ subunit is associated with high levels of resistance to spinosyns in Tuta absoluta (Meyrick) (Lepidoptera: Gelechiidae). Pestic Biochem Physiol 131:1-8. https:// doi.org/10.1016/j.pestbp.2016.02.006

Somers J, Nguyen J, Lumb C et al (2015) In vivo functional analysis of the Drosophila melanogaster nicotinic acetylcholine receptor D $\alpha 6$ using the insecticide spinosad. Insect Biochem Mol Biol 64:116-127. https://doi.org/10.1016/j.ibmb.2015.01.018

Somers J, Luong HNB, Batterham P, Perry T (2017) Deletion of the nicotinic acetylcholine receptor subunit gene D $\alpha 1$ confers insecticide resistance, but at what cost? Fly (Austin) 12:46-54. https:// doi.org/10.1080/19336934.2017.1396399

Ureña E, Guillem-Amat A, Couso-Ferrer F et al (2019) Multiple mutations in the nicotinic acetylcholine receptor $\mathrm{Cc} \alpha 6$ gene associated with resistance to spinosad in medfly. Sci Rep 9:2961. https://doi. org/10.1038/s41598-019-38681-w

Vontas J, Hernández-Crespo P, Margaritopoulos JT et al (2011) Insecticide resistance in Tephritid flies. Pestic Biochem Physiol 100:199-205. https://doi.org/10.1016/j.pestbp.2011.04.004

Wang D, Qiu X, Wang H et al (2010) Reduced fitness associated with spinosad resistance in Helicoverpa armigera. Phytoparasitica 38:103-110. https://doi.org/10.1007/s12600-009-0077-9

Wang J, Wang X, Lansdell SJ et al (2016) A three amino acid deletion in the transmembrane domain of the nicotinic acetylcholine receptor $\alpha 6$ subunit confers high-level resistance to spinosad in Plutella xylostella. Insect Biochem Mol Biol 71:29-36. https:// doi.org/10.1016/j.ibmb.2016.02.001

Watson GB, Chouinard SW, Cook KR et al (2010) A spinosyn-sensitive Drosophila melanogaster nicotinic acetylcholine receptor identified through chemically induced target site resistance, resistance gene identification, and heterologous expression. Insect Biochem Mol Biol 40:376-384. https://doi.org/10.1016/j.ibmb.2009.11.004

Wu M, Robinson JE, Joiner WJ (2014) SLEEPLESS is a bifunctional regulator of excitability and cholinergic synaptic transmission. Curr Biol 24:621-629. https://doi.org/10.1016/j.cub.2014.02.026

Wyss CF, Young HP, Shukla J, Roe RM (2003) Biology and genetics of a laboratory strain of the tobacco budworm, Heliothis virescens (Lepidoptera: Noctuidae), highly resistant to spinosad. Crop Prot 22:307-314. https://doi.org/10.1016/S0261-2194(02)00153-9

Publisher's Note Springer Nature remains neutral with regard to jurisdictional claims in published maps and institutional affiliations. 